\title{
Isoquinolone Syntheses by Annulation Protocols
}

\author{
Ruimao Hua (D)
}

check for updates

Citation: Hua, R. Isoquinolone Syntheses by Annulation Protocols. Catalysts 2021, 11, 620. https:// doi.org/10.3390/catal11050620

Academic Editor: Gianluigi Albano

Received: 21 April 2021

Accepted: 9 May 2021

Published: 11 May 2021

Publisher's Note: MDPI stays neutral with regard to jurisdictional claims in published maps and institutional affiliations.

Copyright: (C) 2021 by the author. Licensee MDPI, Basel, Switzerland. This article is an open access article distributed under the terms and conditions of the Creative Commons Attribution (CC BY) license (https:// creativecommons.org/licenses/by/ $4.0 /)$.
Key Laboratory of Organic Optoelectronics \& Molecular, Department of Chemistry, Tsinghua University, Engineering of Ministry of Education, Beijing 100084, China; ruimao@mail.tsinghua.edu.cn

\begin{abstract}
Isoquinolones (isoquinolin-1(2H)-ones) are one of the important nitrogen-heterocyclic compounds having versatile biological and physiological activities, and their synthetic methods have been recently developed greatly. This short review illustrates the significant advances in the construction of isoquinolone ring with atom- and step-economy, focusing on the intermolecular annulation protocols and intramolecular cyclization in the presence of a variety of catalyst systems. The syntheses of isoquinolone-fused rings are also included.
\end{abstract}

Keywords: alkyne; annulation; isoquinolone; polycyclic-fused isoquinolone

\section{Introduction}

Annulation protocols with unsaturated hydrocarbons are important and efficient methods for syntheses of cyclic compounds with high atom-utilization and step-economy, which have been extensively investigated in synthetic chemistry [1-10]. Isoquinolones are not only interesting and important nitrogen-heterocyclic compounds showing versatile biological and physiological activities but also useful synthetic blocks [11-14]. Several efficient approaches are available for the syntheses of isoquinolones, and the reported early works include the reactions of pyrroline-2,3-diones with benzyne [15], using dilithiated $N$-propenyl-ortho-toluamides [16], dilithiated 2-methyl- $N$-aryl-benzamides [17] as intermediates, and multi-step including $S_{N} A r$ reaction [18].

Over the past decades, isoquinolone ring construction through inter-/intramolecular annulation protocols of unsaturated hydrocarbons with nitrogen-containing reaction partners have been rapidly developed by the activation of aryl $C-H$ and aryl $C-X(X=$ halogen $)$ bonds, as well as $\mathrm{N}-\mathrm{H}$ or $\mathrm{N}-\mathrm{O}$ bonds. This short review provides an overview of the recent advances on this theme.

\section{Isoquinolone Formation via [4 + 2] Intermolecular Annulations and Analogous Reactions}

The cyclocondensation of benzamide derivatives and functionalized arenes with alkynes or C2 synthons have been recently made great progress for the efficient access to isoquinolones via a $[4+2]$ annulation manner. The computational studies on the transition-metal-catalyzed aryl $\mathrm{C}-\mathrm{H}$ oxidative cyclocondensation of benzamides with alkynes affording isoquinolones have also been reported [19].

\section{1. [4 + 2]. Intermolecular Annulations via Aryl C-X/N-H Activation}

The [4 +2] intermolecular annulations of ortho-halobenzamides with alkynes via activation of aryl $\mathrm{C}-\mathrm{X}(\mathrm{X}=$ halogen $) / \mathrm{N}-\mathrm{H}$ bond affording $\mathrm{N}$-substituted isoquinolones have been extensively studied in the presence of nickel complexes under different conditions (Scheme 1). The general proposed mechanism includes the oxidative addition of orhto-halobenzamide to nickel (0) generated in situ in the presence of base leading to the formation of nickelacycle, coordinative insertion of alkyne into the nickelacycle giving possible two seven-membered ring nickelacycle intermediates, followed by reductive elimination affording isoquinolinone [20]. 
C-X/N-H activation

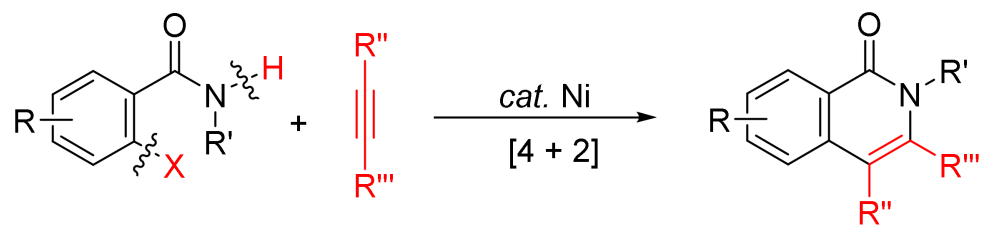

$\left.\begin{array}{r}\text { C-X oxidative } \\ \text { addition to } N i(0)\end{array}\right\} \begin{aligned} & \text { base } \\ & \mathrm{HX} \cdot \text { base }\end{aligned}$

$\mathrm{Ni}(0) \leadsto \begin{aligned} & \text { reductive } \\ & \text { elimination }\end{aligned}$

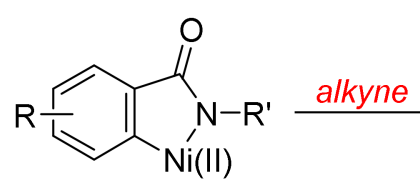

five-membered nickelacycle

$\mathrm{X}=\mathrm{F}, \mathrm{Cl}, \mathrm{Br}, \mathrm{I}$<smiles>[R]C1=C([R7])N([R])C(=O)c2cc[R]([O-])cc2N1</smiles>

Scheme 1. Isoquinolone formation by [4+2] intermolecular annulation of ortho-halobenzamides with alkynes via $\mathrm{C}-\mathrm{X} / \mathrm{N}-\mathrm{H}$ activation.

With the use of air-stable [Ni(dppe) $\mathrm{Br}_{2}$ ] as catalyst, in the presence of $\mathrm{Zn}$ and $\mathrm{Et}_{3} \mathrm{~N}$, the reactions of ortho-halobenzamide with internal alkynes afford $N$-substituted isoquinolone derivatives ( $\mathrm{R}^{\prime}=$ alkyl, allyl, benzyl, aryl) in good to high yields [20]. In the cases of unsymmetric internal alkynes and terminal alkynes used, the cyclocondensation shows regioselective manner, and the catalytic procedure can be used for the synthesis of isoquinolinone alkaloid natural products.

$\mathrm{Ni}(\mathrm{dppp}) \mathrm{Cl}_{2}$ can also catalyze the annulation of ortho-iodobenzamides with alkynes in the presence of $\mathrm{Et}_{3} \mathrm{~N}$ in $\mathrm{MeCN}$ by selective cleavage of $\mathrm{C}-\mathrm{I} / \mathrm{N}-\mathrm{H}$ bond [21]. Very recently, $\mathrm{Ni}(\mathrm{cod})_{2} / \mathrm{KO}^{t} \mathrm{Bu}$-catalyzed formation of highly substituted isoquinolones through cyclocondensation of ortho-fluorobenzamides with internal alkynes via $\mathrm{C}-\mathrm{F} / \mathrm{N}-\mathrm{H}$ activation has also been reported [22].

With the use of ortho-haloarylamidines as substrates, in the presence of $\mathrm{H}_{2} \mathrm{O}$ and zinc, $\mathrm{Ni}(\mathrm{dppp}) \mathrm{Cl}_{2}$-catalyzed annulations with terminal and internal alkynes affords $\mathrm{N}$-aryl isoquinolones in good to high yields (Scheme 2) [23].

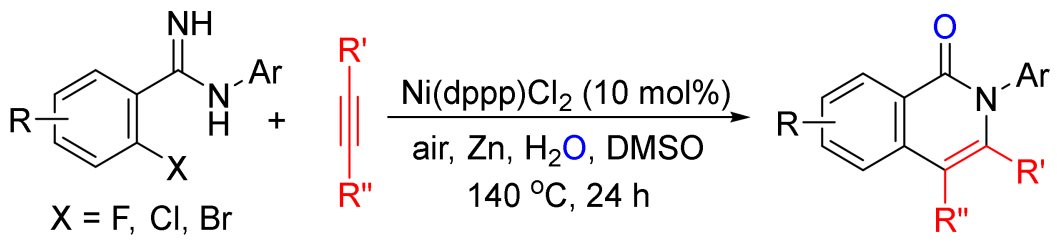

ortho-haloarylamidines

$$
\begin{array}{r}
X=C l, R=R^{\prime \prime}=H, A r=R^{\prime}=P h, 81 \% \\
R=H, A r=R^{\prime}=R^{\prime \prime}=P h, 82 \% \\
R=H, A r=R^{\prime}=P h, R^{\prime \prime}=M e, 95 \% \\
X=B r, R=R^{\prime \prime}=H, A r=R^{\prime}=P h, 88 \%
\end{array}
$$

Scheme 2. Nickel-catalyzed annulation of ortho-haloarylamidines with alkynes affording $N$-aryl isoquinolones. 
$\beta$-Keto esters are used as a C2 synthon in the formation of isoquinolones via [ $4+2]$ cyclocondensation with ortho-halobenzamides [24]. As shown in Scheme 3, CuI-catalyzed reactions of ortho-chloro, -bromo-, and -iodobenzamides or ortho-chloronicotinamide with $\beta$-keto esters in the presence of $\mathrm{Cs}_{2} \mathrm{CO}_{3}$ without addition of any ligand or additive afford 3,4-disubstituted $\mathrm{N}-\mathrm{H}$ isoquinolone derivatives in moderate to high yields.<smiles>[X]c1ccccc1C(N)=O</smiles>

$\mathrm{E}=\mathrm{CH}, \mathrm{N}$<smiles>[R]C(=O)CC(=O)O[K]</smiles>

$\mathrm{R}^{\prime}=\mathrm{alkyl}, \mathrm{Ph}$

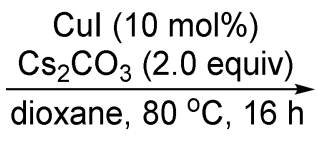

$$
\begin{aligned}
& R=H, R^{\prime}=M e, R^{\prime \prime}=E t \\
& E=C H, X=C l, 35 \% ; B r, 80 \% ; I, 83 \% \\
& E=N, X=C l, 60 \%
\end{aligned}
$$

Scheme 3. CuI-catalyzed synthesis of 3,4-disubstituted isoquinolones.

In addition, as shown in Scheme 4, in the presence of $\mathrm{Pd}(\mathrm{OAc})_{2}$ and $\mathrm{P}^{t} \mathrm{Bu}_{3} \mathrm{HBF}_{4}$, norbornadiene can also be used as an acetylene equivalent in the synthesis of 3,4-unsubstituted $\mathrm{N}$ benzyl isoquinolones via the annulation with ortho-chlorobenzamides [25]. $\mathrm{A} \mathrm{Cu}(\mathrm{OAc})_{2} \cdot \mathrm{H}_{2} \mathrm{O}-$ catalyzed cyclocoupling reaction of $\mathrm{N}$-substituted ortho-iodo-benzamides with malononitrile afforded $\mathrm{N}$-substituted-3-amino-4-cyano-isoquinolones in good to high yields, and malononitrile is used as C2 synthon [26].
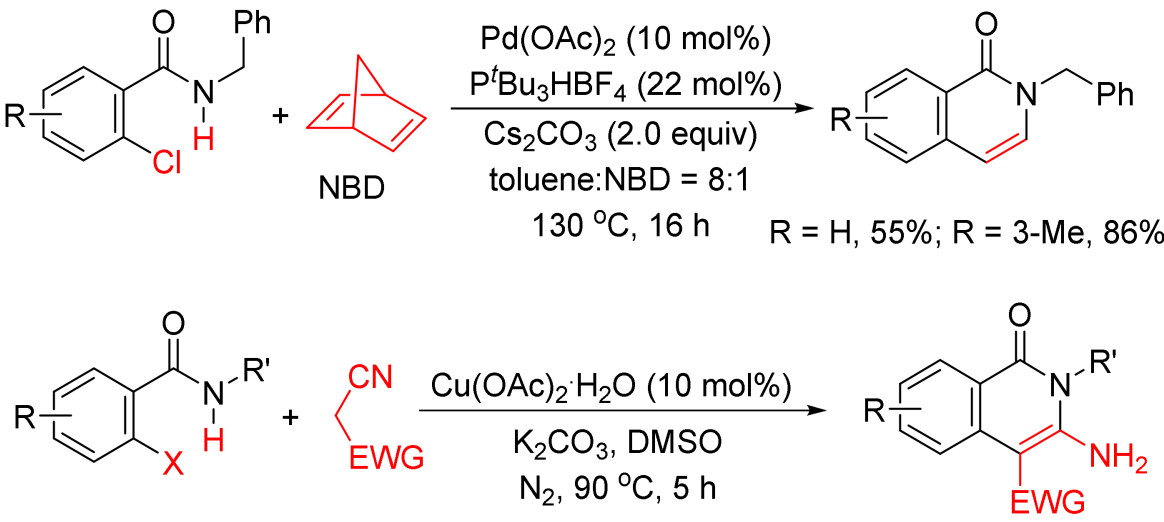

$\mathrm{X}=\mathrm{I}, \mathrm{Br}$

EWG: electron-withdrawing group

$$
\begin{array}{r}
X=I, R=H, E W G=C N, R^{\prime}=P h, 99 \% \\
R^{\prime}=n-C_{6} H_{13}, 77 \% \\
R^{\prime}=\text { ally, } 96 \% \\
X=B r, R=H, R^{\prime}=P h, E W G=C N, 35 \% \\
X=I, R=H, R^{\prime}=P h, E W G=\text { COOEt, } 93 \%
\end{array}
$$

Scheme 4. Isoquinolone formation by cyclocoupling reactions of ortho-halobenzamides with norbornadiene or malononitrile.

The formation of functionalized isoquinolones by copper-catalyzed cyclocondensation of ketones with ortho-halobenzamides [27] or ortho-halobenzonitriles [28] through $\mathrm{S}_{N} \mathrm{Ar}$ reaction giving $\alpha$-aryl ketones as the intermediates have also been reported (Scheme 5). 


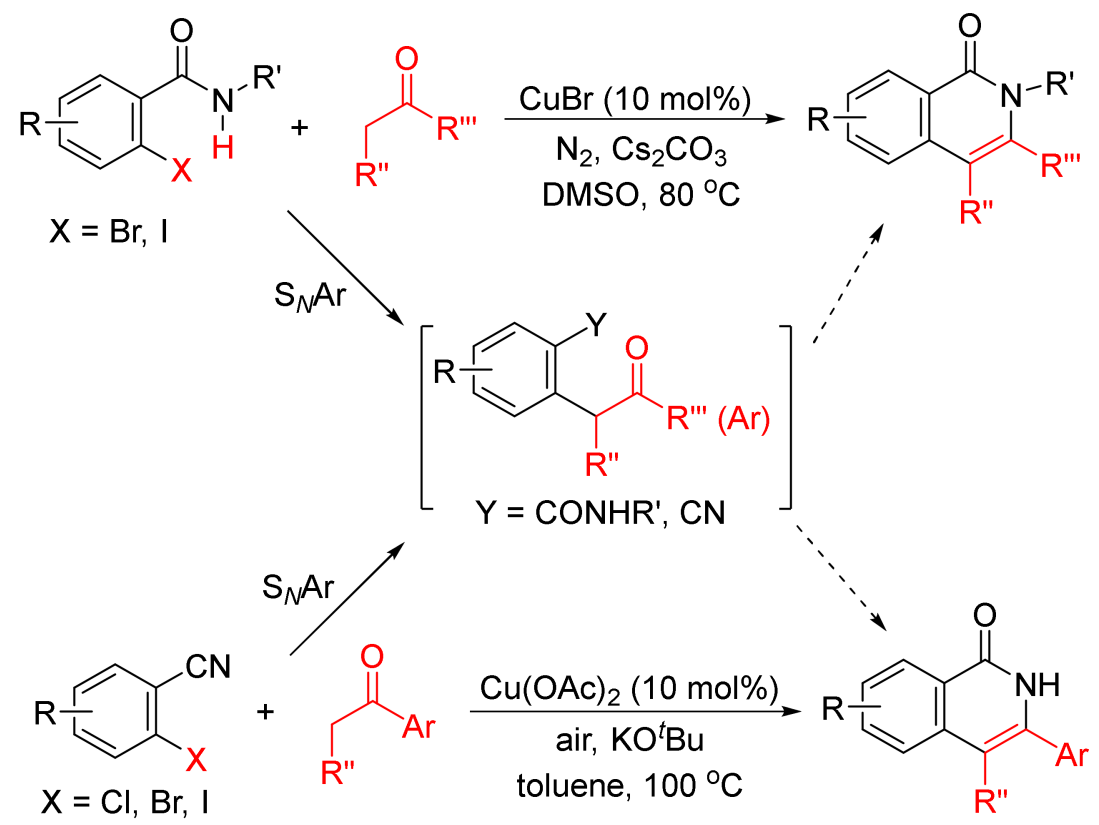

Scheme 5. Copper-catalyzed isoquinolone formation including $S_{N}$ Ar reaction.

2.2. [4 + 2]. Intermolecular Annulations via Aryl C-H/N-O Activation Access to N-H Isoquinolones

Transition-metal-catalyzed annulations of alkynes with $N$-alkoxybenzamides by $\mathrm{C}$ $\mathrm{H} / \mathrm{N}-\mathrm{O}$ bond cleavages with dealkoxylation reaction have been extensively investigated for the formation of $\mathrm{N}-\mathrm{H}$ isoquinolones (Scheme 6).

\section{C-HIN-O activation}

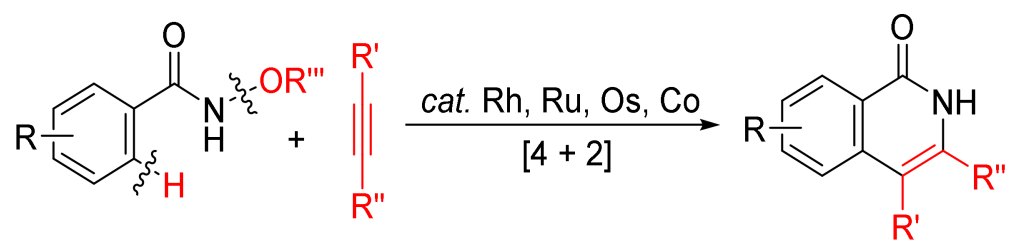

Scheme 6. Isoquinolone formation by [4 +2$]$ intermolecular annulation of $N$-alkoxybenzamides with alkynes via $\mathrm{C}-\mathrm{H} / \mathrm{N}-\mathrm{O}$ activation.

Guimond and coworkers first studied the cyclocondensation of $\mathrm{N}$-alkoxybenzamides with internal alkynes catalyzed by $\left[\mathrm{Cp}^{*} \mathrm{RhCl}_{2}\right]_{2} / \mathrm{CsOAc}$ in methanol to synthesize $\mathrm{N}-$ $\mathrm{H}$ isoquinolones via $\mathrm{C}-\mathrm{H} / \mathrm{N}-\mathrm{O}$ bond activation in 2010 , and the mechanism was also investigated in detail $[29,30]$. The group $\mathrm{CONH}(\mathrm{OMe})$ is used as an oxidizing directing group, and the transformation occurs under external oxidant-free conditions.

The same catalyst system was then applied in the intramolecular reaction of alkynetethered $N$-alkoxybenzamides leading to a general and facile synthesis of 3-hydroxyalkylsubstituted $\mathrm{N}-\mathrm{H}$ isoquinolones as the major products, and one of them can be used in the synthesis of natural product of Rosettacin, which is a polycyclic-fused isoquinolone derivative (Scheme 7) [31].

Similar conditions were then applied by other groups in the [4 +2$]$ cyclocondensation of $N$-pivaloyloxy benzamides with vinyl acetate [32], cyclopropenes [33], and substituted allenes [34] to develop the synthesis of 3,4-unsubstituted $\mathrm{N}-\mathrm{H}$ isoquinolones and 3- or/and 4-substituted $\mathrm{N}-\mathrm{H}$ isoquinolones (Scheme 8). In the case of the vinyl acetate used, it emerges as the convenient acetylene equivalent. 


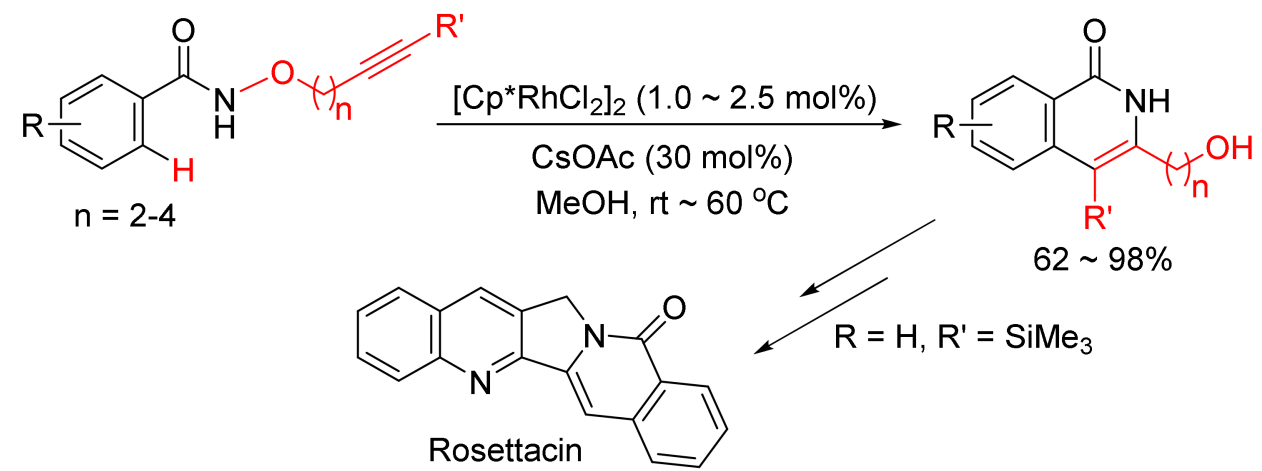

Scheme 7. Synthesis of Rosettacin.

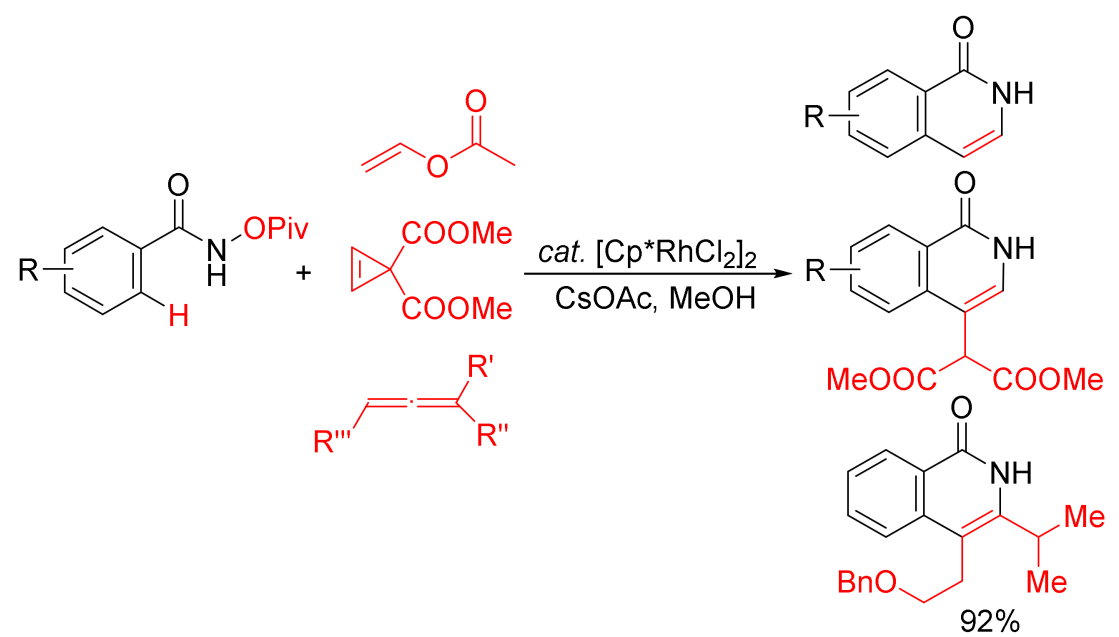

Scheme 8. $\mathrm{Rh}(\mathrm{III})$-catalyzed $\mathrm{C}-\mathrm{H} / \mathrm{N}-\mathrm{O}$ activation/annulation of $\mathrm{N}$-OPiv benzamides with vinyl esters, cyclopropenes, and allenes affording $\mathrm{N}-\mathrm{H}$ isoquinolones.

In addition, 3,4-unsubstituted $\mathrm{N}-\mathrm{H}$ isoquinolones can also be synthesized by annulation of benzoic acid with $\mathrm{N}$-vinyl formamide catalyzed by $\left[\mathrm{Cp} * \mathrm{RhCl}_{2}\right]_{2}$ in the presence of $\mathrm{AgOAc}$ and $\mathrm{KHCO}_{3}$ in benzonitrile at $80{ }^{\circ} \mathrm{C}$ [35].

Thereafter, catalysis of [Cp* $\left.\mathrm{RhCl}_{2}\right]_{2} / \mathrm{Bu}_{4} \mathrm{NOAc}$ in DCE [36], $\left[\mathrm{RuCl}_{2} \text { (p-cymene) }\right]_{2} / \mathrm{NaOAc}$ in $\mathrm{MeOH}[37,38],\left[\mathrm{RuCl}_{2} \text { (p-cymene) }\right]_{2} / \mathrm{KO}_{2} \mathrm{CMes}$ in water [39], $\left[\mathrm{RuCl}_{2} \text { (p-cymene) }\right]_{2} / \mathrm{KO}_{2} \mathrm{CMes} /$ $\mathrm{Cu}(\mathrm{OAc})_{2} \cdot \mathrm{H}_{2} \mathrm{O}$ in $\mathrm{CHCl}_{3}$ [40], [Os( $p$-cymene) $\left.\mathrm{Cl}_{2}\right]_{2} / \mathrm{NaOAc} / \mathrm{HOAc}$ in trifluoroethanol (TFE) [41], and $\mathrm{Co}(\mathrm{OAc})_{2} \cdot 4 \mathrm{H}_{2} \mathrm{O} / \mathrm{AgOAc} / \mathrm{PivOH}$ in TFE [42] have been developed to synthesize $\mathrm{N}-\mathrm{H}$ isoquinolones from the reactions of secondary $\mathrm{N}$-alkoxybenzamides with internal alkynes via selective $\mathrm{N}-\mathrm{O}$ bond cleavage. The use of free hydroxamic acids is also successful to give the corresponding isoquinolones [39].

In addition, $\left[\mathrm{RuCl}_{2}(p \text {-cymene) }]_{2} / \mathrm{NaOAc}\right.$ in $\mathrm{MeOH}$ can be applied in the reactions of $\mathrm{N}$-methoxybenzamide with alkynyl bromides affording 3-methoxy-4-substituted $\mathrm{N}-\mathrm{H}$ isoquinolinones with excellent chemoselectivity via $\mathrm{C}-\mathrm{H} / \mathrm{N}-\mathrm{O}$ activation [43]. Recently, the same catalyst system has been applied in the intramolecular cyclo-isomerization of alkynetethered $\mathrm{N}$-alkoxybenzamides to give 3,4-disubstituted $\mathrm{N}-\mathrm{H}$ isoquinolones (Scheme 9) [44]. The experimental and theoretical studies indicate that the reaction to the inverse annulation follows the $\mathrm{Ru}(\mathrm{II})-\mathrm{Ru}(\mathrm{IV})-\mathrm{Ru}(\mathrm{II})$ pathway involving $\mathrm{N}-\mathrm{O}$ bond cleavage prior to alkyne insertion. 


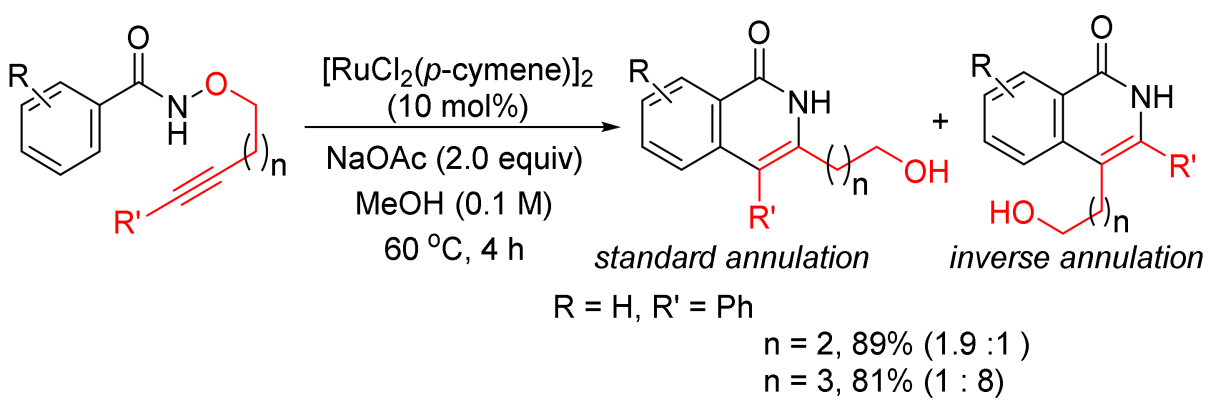

Scheme 9. Ruthenium-catalyzed cascade $\mathrm{C}-\mathrm{H}$ activation/annulation of alkyne-tethered $\mathrm{N}$ alkoxybenzamides.

Moreover, the functionalized arenes have also been used as the coupling partners in the $[4+2]$ annulations with alkynes to construct isoquinolone ring via activation of aryl $\mathrm{C}-\mathrm{H}$ and $\mathrm{N}-\mathrm{E}(\mathrm{E}=\mathrm{N}, \mathrm{C}, \mathrm{O}, \mathrm{Cl}$, etc.) bonds. As shown in Scheme 10, with the use of $\left[\mathrm{Cp}^{*} \mathrm{RhCl}_{2}\right]_{2}$ as catalyst, the annulations of alkynes with benzoyl hydrazines (Scheme 10 (a)) [45], with 1,4,2-dioxazol-5-ones occur at room temperature (Scheme 10 (b)) [46], with $\mathrm{N}$-iminopyridinium ylides (Scheme 10 (c)) [47]. However, with the use of $\mathrm{AgNTf}_{2}$ as co-catalyst, the reactions of 2-aryloxazolines with alkynes afford $\mathrm{N}$-substituted isoquinolones (Scheme $10(\mathrm{~d}))$ [48].

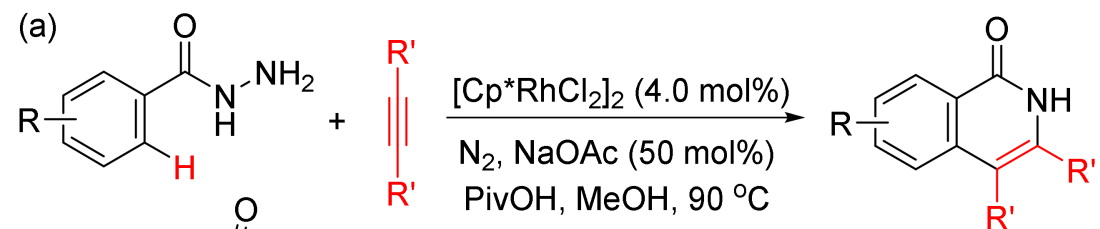

(b)

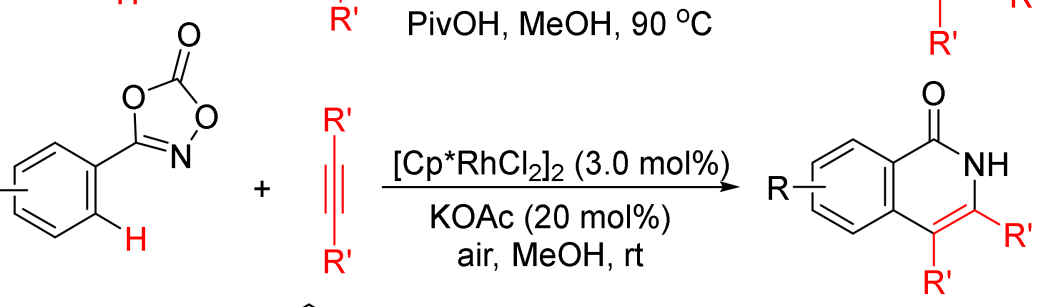

(c)
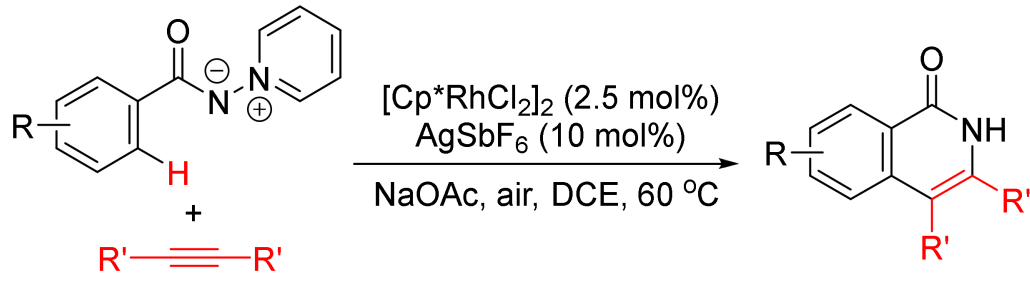

(d)<smiles>CC1COC(c2cc[R]cc2)=N1</smiles>

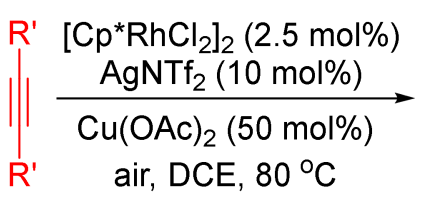<smiles>[R]c1c([R])n(C(C)COC(C)=O)c(=O)c2cc[R][c]c12</smiles>

Scheme 10. Isoquinolone formation by rhodium (III)-catalyzed annulation of alkynes with different aryl substrates.

In the presence of $\mathrm{KOAc},\left[\mathrm{Cp}{ }^{*} \mathrm{Co}(\mathrm{CO}) \mathrm{I}_{2}\right] / \mathrm{AgOAc}$-catalyzed [4 + 2] annulation of $\mathrm{N}$ chlorobenzamides with alkynes in TFE occurs at room temperature with selective cleavage of $\mathrm{C}-\mathrm{H} / \mathrm{N}-\mathrm{Cl}$ bonds (Scheme 11) [49]. In the case of the use of terminal alkyne, the reactions occur with high regioselectivity to give 3 -substituted $\mathrm{N}-\mathrm{H}$ isoquinolones. 


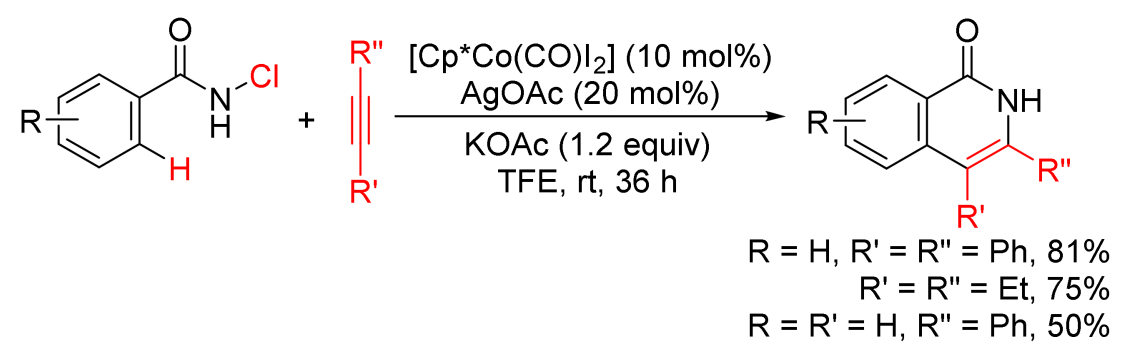

Scheme 11. $\mathrm{N}-\mathrm{H}$ isoquinolone formation by cobalt-catalyzed cyclocondensation of $N$-chloroamides with alkynes.

\section{3. [4 + 2]. Intermolecular Annulations via Aryl $\mathrm{C}-\mathrm{H} / \mathrm{N}-\mathrm{H}$ Activation}

More atom-economical procedures for the formation of isoquinolones is the oxidative [4 + 2] cyclocondensation of primary and secondary benzamides with internal alkynes with selective cleavages of $\mathrm{C}-\mathrm{H}$ and $\mathrm{N}-\mathrm{H}$ bonds (Scheme 12).

C-H/N-H activation

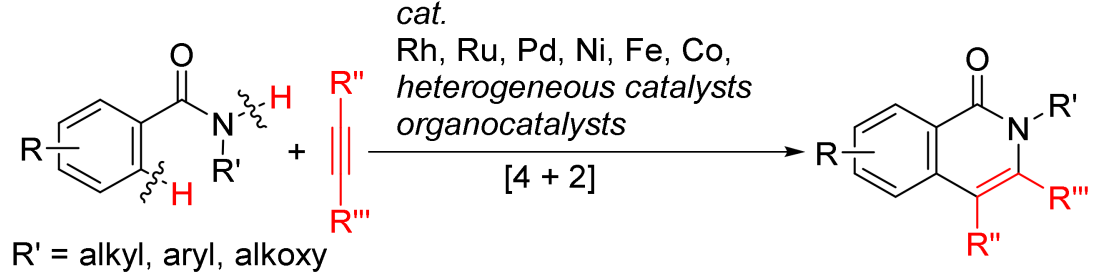

Scheme 12. Isoquinolone formation by [4 +2] intermolecular annulation of benzamides with alkynes via $\mathrm{C}-\mathrm{H} / \mathrm{N}-\mathrm{H}$ activation.

Miura and Satoh's group reported the oxidative coupling of primary, secondary, and tertiary benzamides with internal alkynes catalyzed by rhodium complexes and with the use of $\mathrm{Cu}(\mathrm{OAc})_{2} \cdot 2 \mathrm{H}_{2} \mathrm{O}$ as oxidant in 2010 [50]. As shown in Scheme 13, the reaction between primary benzamides with internal alkynes affords isoquinoline-fused polycyclic aromatics resulting from two incorporated molecules of alkynes. In the case of secondary benzamides, $N$-substituted isoquinolones are formed. Interestingly, the reaction of tertiary benzamides with internal alkynes under similar conditions produces 1-naphthalenecarboxamides through double aryl C-H bond activation (Scheme 14).

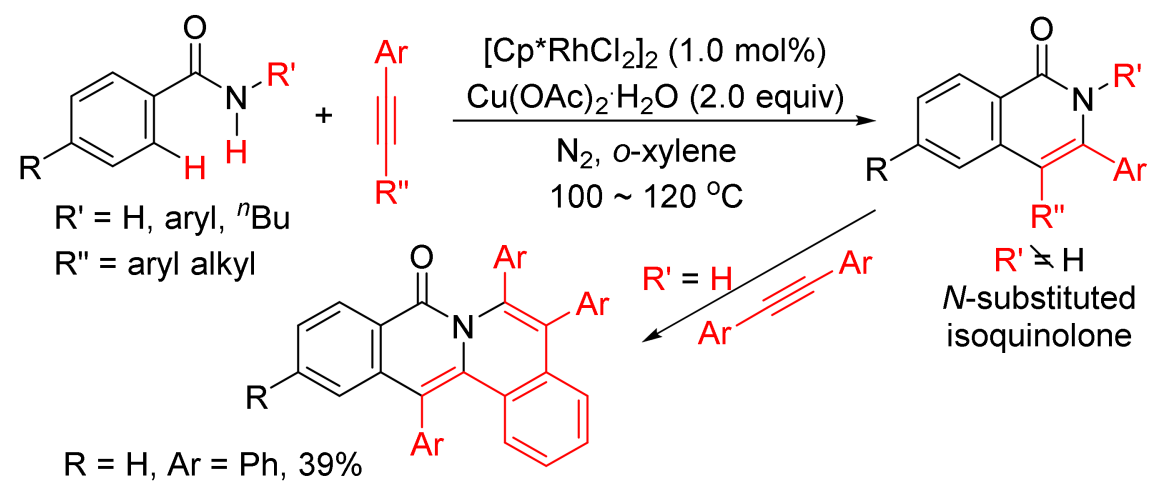

Scheme 13. Rhodium-catalyzed cyclocondensation of primary/secondary benzamides with internal alkynes affording isoquinolones and fused isoquinolone. 


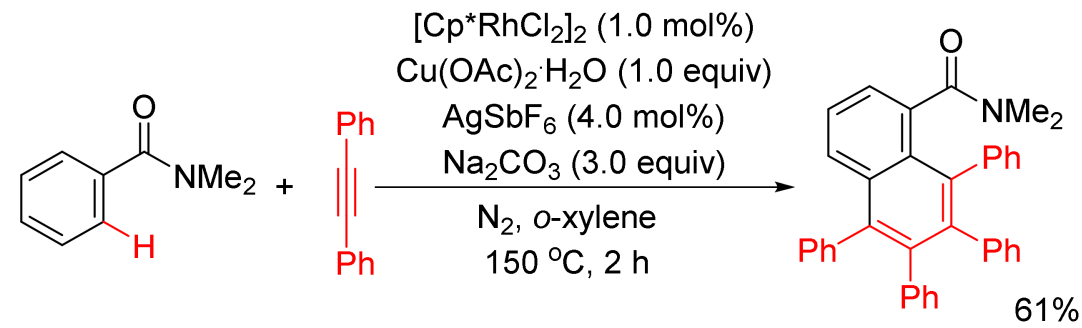

Scheme 14. Rhodium-catalyzed oxidative coupling of tertiary benzamides with internal alkynes.

In the same year, two similar works were also reported using $\left[\mathrm{Cp} * \mathrm{RhCl}_{2}\right]_{2}$ as catalyst to synthesize $\mathrm{N}$-substituted isoquinolones by oxidative/cyclization of benzamides with internal alkynes via selective aryl $\mathrm{C}-\mathrm{H} / \mathrm{N}-\mathrm{H}$ bonds cleavage [51,52]. Other rhodium catalysis of $\left[\mathrm{Cp} * \mathrm{Rh}(\mathrm{MeCN})_{3}\right] \mathrm{BF}_{4} / \mathrm{K}_{2} \mathrm{CO}_{3}$ in water under air was then developed [53].

Although $\left[\mathrm{RuCl}_{2}(p \text {-cymene) }]_{2}\right.$-catalyzed annulations of $N$-alkoxybenzamides $\left(\mathrm{R}^{\prime}=\right.$ alkoxy $)$ with internal alkynes occur with dealkoxylation reactions via activation of $\mathrm{N}-\mathrm{O}$ bond to give $\mathrm{N}-\mathrm{H}$ isoquinolones [37-40], with the use of $\mathrm{Cu}(\mathrm{OAc})_{2} \cdot \mathrm{H}_{2} \mathrm{O}$ as the terminal oxidant and $t-$ $\mathrm{AmOH}$ as the solvent, the oxidative annulation of $\mathrm{N}$-alkyl/arylbenzamides $\left(\mathrm{R}^{\prime}=\right.$ alkyl, aryl) with internal alkynes gives efficient access to $N$-alkyl/aryl-substituted isoquinolones by highly selective cleavage of $\mathrm{N}-\mathrm{H}$ bond $[54,55]$.

In addition, when $\mathrm{Pd}(\mathrm{OAc})_{2}$ was used as a catalyst, in the presence of $\mathrm{NaI} \cdot 2 \mathrm{H}_{2} \mathrm{O}$ as additive, the methoxy substituent on nitrogen $\left(\mathrm{R}^{\prime}=\right.$ alkoxy $)$ was not cleaved during the catalysis under air, and the formation of $\mathrm{N}$-methoxy isoquinolones had high chemoselectivity (Scheme 15) [56,57]. Under similar reaction conditions, using $\mathrm{Cu}(\mathrm{II})$ salts as the co-oxidants, a broad range of $\mathrm{N}$-alkyl and $\mathrm{N}$-aryl-substituted isoquinolones can also be obtained starting from $\mathrm{N}$-alkyl/aryl benzamides, and N-C bonds are not cleaved either [58]. The mechanistic studies propose that the use of stoichiometric amount of $\mathrm{Cu}$ (II) salts as the key oxidant and air as the terminal oxidant are key for the regeneration of active $\operatorname{Pd}(\mathrm{II})$ species.

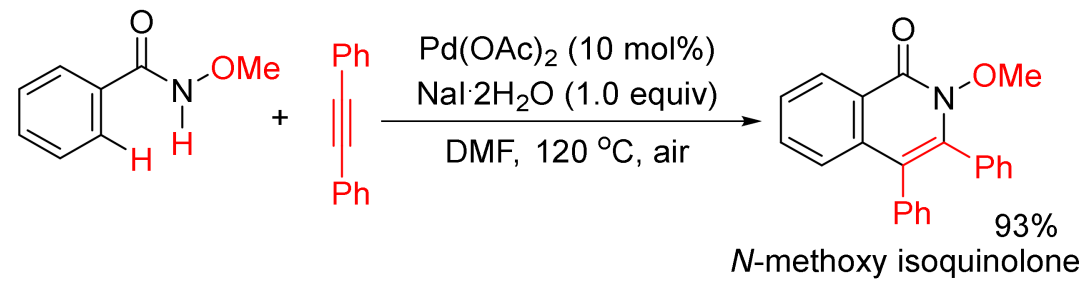

Scheme 15. N-Methoxy isoquinolone formation via highly chemoselective N-H activation.

A similar catalyst system was then applied in the oxidative annulation of $N$-methoxybe nzamides with arynes and cyclooctynes via $\mathrm{C}-\mathrm{H} / \mathrm{N}-\mathrm{H}$ activation for the synthesis of fused isoquinolones [59]. Very recently, the annulation of benzamides with arynes using palladium with photoredox dual catalysis has also been developed for the synthesis of benzo-fused isoquinolones [60].

The formation of $\mathrm{N}$-alkyl-, aryl-, or alkoxy-substituted isoquinolones by the oxidative [4 +2] cyclocondensation of secondary benzamides with internal alkynes with selective cleavages of $\mathrm{C}-\mathrm{H}$ and $\mathrm{N}-\mathrm{H}$ bonds has been achieved using other transition-metal catalyst systems, such as nickel [61,62], iron [63] complexes as catalysts, and heterogeneous catalyst of palladium-nanoparticles [64], $\mathrm{Pd} / \mathrm{C}[65,66]$.

In the presence of $\mathrm{NaOPiv} \cdot \mathrm{H}_{2} \mathrm{O}, \mathrm{Co}(\mathrm{OAc})_{2} \cdot 4 \mathrm{H}_{2} \mathrm{O} / \mathrm{Ag}_{2} \mathrm{O}$-catalyzed decarboxylative $\mathrm{C}-\mathrm{H} / \mathrm{N}-\mathrm{H}$ activation/annulation of $\mathrm{N}-\mathrm{PyO}$ benzamides with alkynyl carboxylic acids under air in TFE also affords 3-substituted isoquinolones with high regioselectivity [67]. Similarly, 3-substituted isoquinolones can be obtained using $\mathrm{Co}(\mathrm{OAc})_{2} \cdot 4 \mathrm{H}_{2} \mathrm{O}$ as catalyst from the reactions of $\mathrm{N}$-(quinolin-8-yl)benzamides with alkynylsilanes with desilylation under oxygen in the same solvent, with the use of $\mathrm{Mn}(\mathrm{acac})_{2}$ and $\mathrm{CsF}$ [68]. 
In addition, the first metal-free annulation of $\mathrm{N}$-methoxybenzamides with internal alkynes was reported by Antonchick's group with the use of $\mathrm{PhI}$ as catalyst and $\mathrm{AcOOH}$ as oxidant in 1,1,1,3,3,3-hexafluoro-2-propanol (HFIP) at room temperature [69]. A mechanism involving the formation of hypervalent iodine reagent of (diacetoxyiodo)benzene (PIDA) is proposed. At the same time, this type of oxidative cycloaddition reaction can also occur using bis(trifluoracetoxy)iodobenzene as oxidant in the presence of trifluoroacetic acid [70].

$\mathrm{Rh}$ (III)-catalyzed annulation of benzoyl hydrazines and alkynes affords isoquinolones with deammoniation by cleavage of $\mathrm{N}-\mathrm{N}$ bond (Scheme $10(\mathrm{a}))$. However, $\left[\mathrm{Ru}\left(p \text {-cymene) } \mathrm{Cl}_{2}\right]_{2} /\right.$ $\mathrm{AgSbF}_{6}$-catalyzed reactions of $\mathrm{N}$-(1H-pyrrolo [2,3-b]pyridin-1-yl)-benzamides with internal alkynes afford isoquinolone derivatives with remaining N-N bond untouched (Scheme 16) [71]. In this procedure, $\mathrm{N}$-amino-7-azaindole is used as an efficient bidentate-directing group to promote the selective $\mathrm{C}-\mathrm{H}$ bond activation.

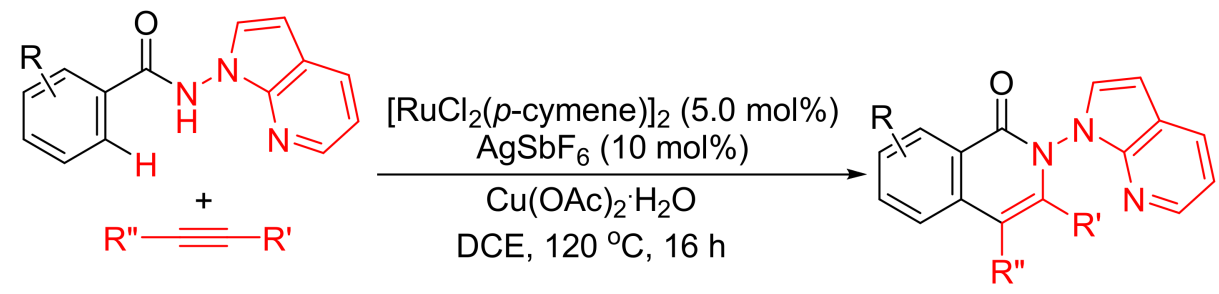

Scheme 16. Ruthenium-catalyzed isoquinolone formation by $\mathrm{N}$-amino-7-azaindole-assisted $\mathrm{C}-\mathrm{H}$ activation.

Instead of internal alkynes, the annulations of benzamides with other $\mathrm{C} 2$ synthons via $\mathrm{C}-\mathrm{H} / \mathrm{N}-\mathrm{H}$ activation to construct isoquinolone ring have also been developed. For example, Glorius and coworkers developed a $\mathrm{Rh}(\mathrm{III})$-catalyzed intermolecular [4 + 2] cyclocondensation of $N$-methoxybenzamides with $\alpha$-halo and pseudohalo ketones to afford various 3-substituted $\mathrm{N}$-methoxyisoquinolones in moderate to excellent yields (Scheme 17) [72]. The $\alpha$-halo and pseudohalo ketones are utilized as oxidized alkyne equivalents to undergo the redox-neutral annulation, and through the formation of orthoacylmethyl-benzamides as the intermediates. Recently, Ma and coworkers have also reported a $\mathrm{Pd}(\mathrm{OAc})_{2} /$ L-alanine-catalyzed formation of 3-substituted $N$-(quinolin-8-yl)isoquinolones with by $\mathrm{N}$-(quinolin-8-yl)benzamides and $\alpha$-bromo ketones in the presence of $\mathrm{K}_{2} \mathrm{CO}_{3}$ in $t-\mathrm{AmOH}$ [73].

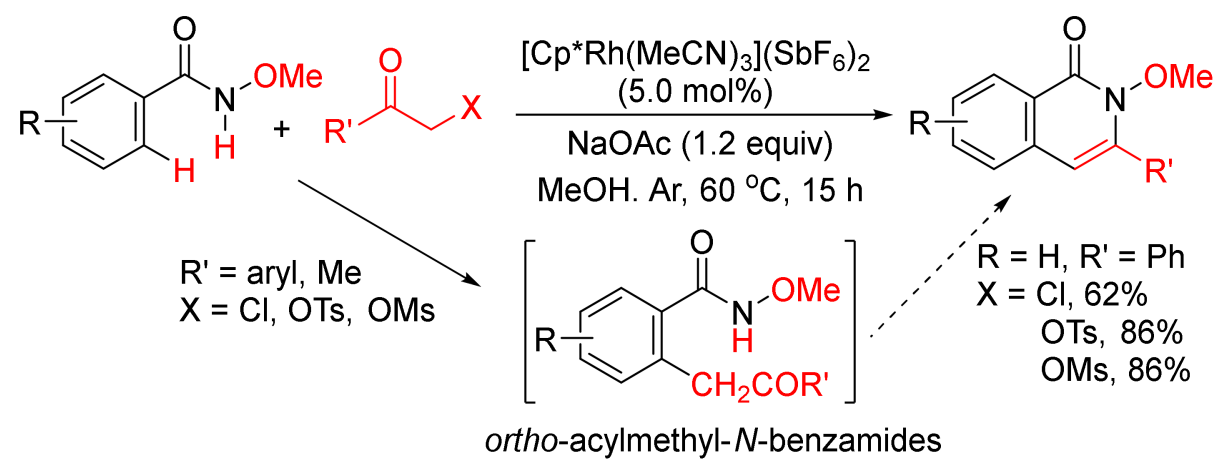

Scheme 17. 3-Substituted isoquinolone synthesis via $\mathrm{Rh}(\mathrm{III})$-catalyzed intermolecular cyclocondensation of $N$-methoxybenzamides with $\alpha$-halo and pseudohalo ketones.

With the use of same rhodium complex, 4-substituted isoquinolones can be obtained by a microwave-assisted annulation of $N$-methoxyamides with $\alpha$-chloroaldehydes (Scheme 18) [74]. 


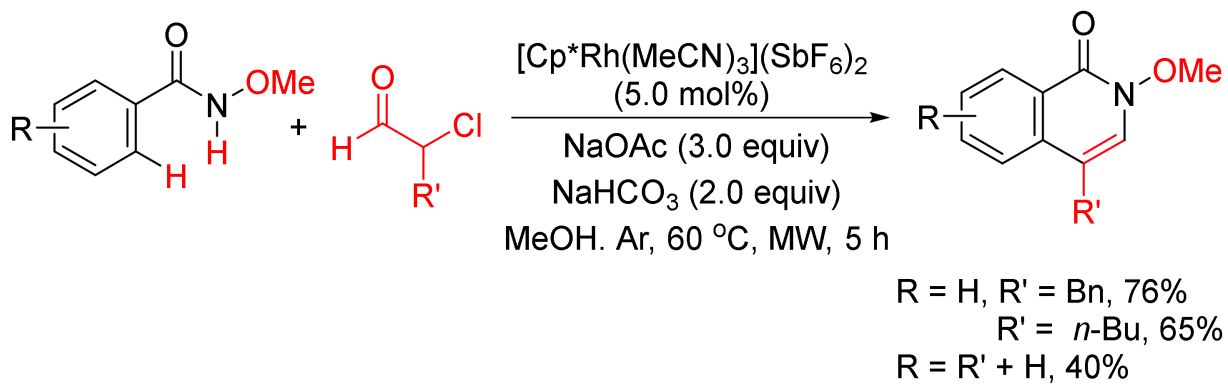

Scheme 18. 4-Substituted isoquinolone formation via microwave-assisted annulation of $N$ methoxyamides with $\alpha$-chloroaldehydes.

Moreover, 3-Cyclohexylmethyl $\mathrm{N}$-methoxyisoquinolone, which was published as only one example in literature [75], can be synthesized by the cyclocondensation of $\mathrm{N}$ methoxyisoquinolone with the corresponding $\alpha$-carbonyl sulfoxonium ylide catalyzed by rhodium in HFIP (Scheme 19). The detailed studies for the formation of 3-substituted isoquinolones through the reactions of $N$-methoxybenzamides and $\alpha$-carbonyl sulfoxonium ylides catalyzed by $\mathrm{Cp}^{*} \mathrm{Rh}(\mathrm{MeCN})_{3}\left(\mathrm{SbF}_{6}\right)_{2} / \mathrm{Zn}(\mathrm{OTf})_{2}$ in DCE were then reported by $\mathrm{Li}$ and coworkers [76].

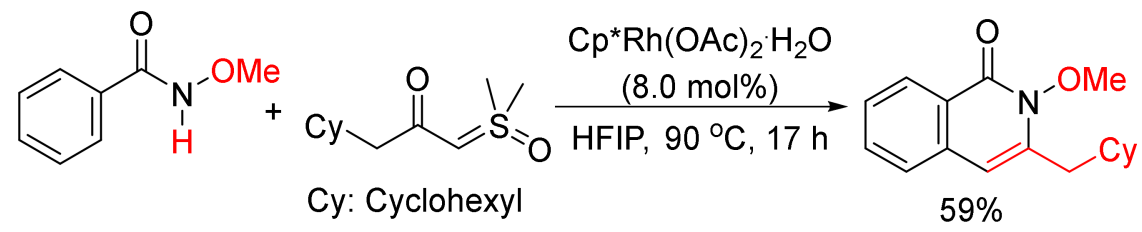

Scheme 19. Rhodium-catalyzed cyclocondensation of $N$-methoxyisoquinolone with $\alpha$-carbonyl sulfoxonium ylide affording 3-substituted isoquinolone.

Very recently, epoxides as alkylating reagents and C2 synthon have been applied in $\mathrm{Pd}(\mathrm{OAc})_{2}$-catalyzed oxidative annulation of $\mathrm{N}$-alkoxybenzamides to regioselectively synthesize 3-substituted isoquinolones in HFIP solvent (Scheme 20) [77]. The present methodology has been successfully employed in the total syntheses of rupreschstyril, siamine, and cassiarin A (Figure 1).

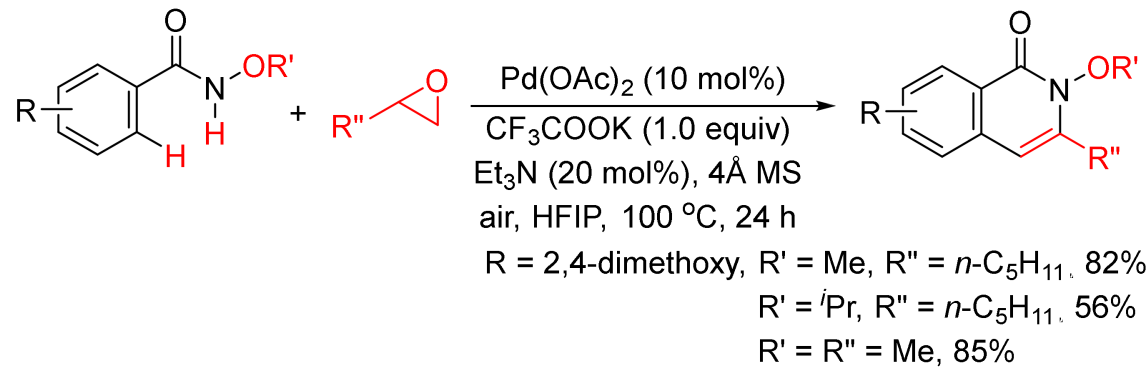

Scheme 20. $\mathrm{Pd}(\mathrm{OAc})_{2}$-catalyzed annulation of epoxides with benzamides.

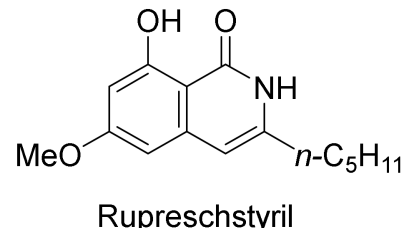

Rupreschstyril<smiles>[M]c1cc2cc(O)cc(O)c2c(=O)[nH]1</smiles>

Siamine<smiles>CC1=Cc2cc(O)cc3cc(C)cc(c23)O1</smiles>

Cassiarin $\mathrm{A}$

Figure 1. Synthetic applications in the total synthesis of natural products. 
In addition, as depicted in Scheme 3, $\beta$-keto esters can be used as a C2 synthon in the formation of isoquinolones via cyclocondensation with ortho-halobenzamides catalyzed by CuI. However, in the presence of $\mathrm{Pd}\left(\mathrm{OOCCF}_{3}\right)_{2}$ and $\mathrm{K}_{2} \mathrm{~S}_{2} \mathrm{O}_{8}$, the reactions of $\mathrm{N}$-alkoxybenzamides with $\beta$-keto esters have also been developed for the synthesis of isoquinolones via selective $\mathrm{C}-\mathrm{H} / \mathrm{N}-\mathrm{H}$ activation [78].

Moreover, as shown in Scheme 21, in the presence of $\left[C \mathrm{p}^{*} \mathrm{RhCl}_{2}\right]_{2}$, the regioselective formation of substituted isoquinolones through cyclocondensation of $\mathrm{N}$-methoxybenzamide [79] or primary benzamides [80] with diazo compounds has also been developed. In the case of $\mathrm{N}$-methoxybenzamide used, $\mathrm{C}-\mathrm{H} / \mathrm{N}-\mathrm{H}$ activation occurs selectively.

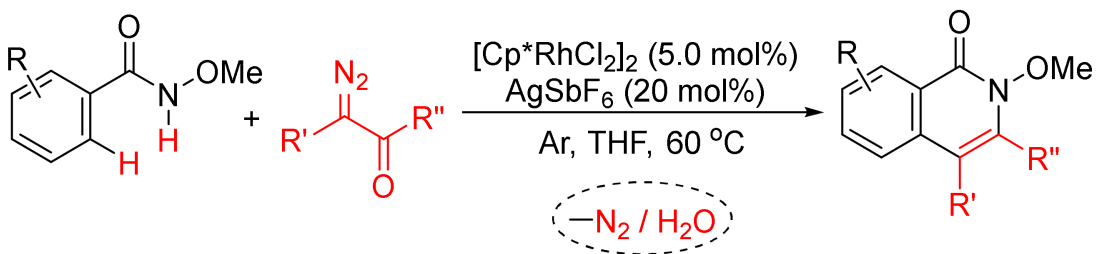

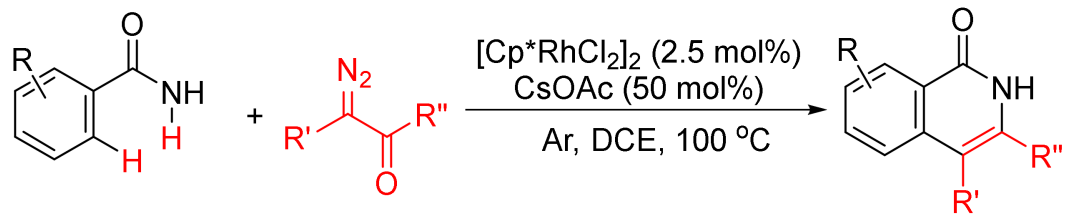

Scheme 21. Approach to isoquinolinones by rhodium-catalyzed annulation of benzamides with diazo compounds.

Similarly, [Cp* $\left.\mathrm{RhCl}_{2}\right]_{2} / \mathrm{KOAc}$-catalyzed intermolecular cyclization between $\mathrm{N}$-methoxy benzamide and 4-diazoisochroman-3-imines provides 3-amino-4-aryliso-quinolones via a selective $\mathrm{N}-\mathrm{O}$ cleavage of 4-diazoisochroman-3-imines (Scheme 22) [81].

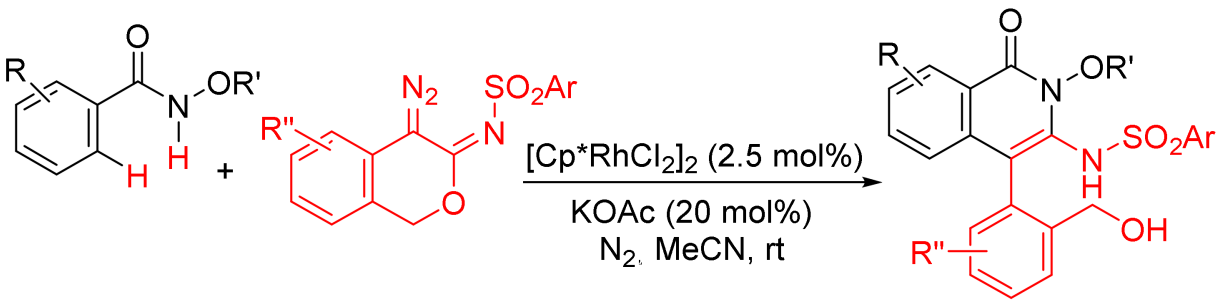

Scheme 22. Rh(III)-catalyzed synthesis of highly substituted isoquinolones from 4-diazoisochroman3-imines and N-alkoxybenzamides.

The construction of isoquinolone ring can also be realized by the annulation of carboncarbon double bonds with benzamides with selective $\mathrm{C}-\mathrm{H} / \mathrm{N}-\mathrm{H}$ activation.

For example, with the use of $\mathrm{Mn}(\mathrm{OAc})_{3} \cdot 2 \mathrm{H}_{2} \mathrm{O}$ as the oxidant and $\mathrm{NaOPiv} \cdot \mathrm{H}_{2} \mathrm{O}$ as the base in TFE, Thrimurtulu and coworkers developed a $\mathrm{Co}(\mathrm{acac})_{2}$-catalyzed isoquinolone synthesis by the intermolecular cyclization between $N$-(quinolin-8-yl)benzamides and substituted allenes at room temperature to give 3-substituted $\mathrm{N}$-(quinolin-8-yl)isoquinolones [82]. In addition, in the presence of $\mathrm{Ag}_{2} \mathrm{CO}_{3}$ and $\mathrm{Cs}_{2} \mathrm{CO}_{3}, \mathrm{Co}(\mathrm{OAc})_{2}$ can catalyze the similar cyclization in the same solvent giving isoquinolones [83].

The catalysts system of $\left[\mathrm{Cp}^{*} \mathrm{Rh}(\mathrm{MeCN})_{3}\right]\left[\mathrm{SbF}_{6}\right]_{2} / \mathrm{Cu}(\mathrm{OAc})_{2}$ in HFIP also shows highly catalytic activity in the cyclocondensation of $\mathrm{N}$-methoxybenzamides with nitroalkenes for the selective synthesis of 4-substituted $N$-methoxyisoquinolones [84].

\section{Isoquinolone Syntheses via [5+1] Intermolecular Annulation between Ortho-(1-Alkynyl)Benzaldehyde and Primary Amines}

Readily available ortho-(1-alkynyl)benzaldehydes have been well-applied in the synthesis of benzo-fused heterocycles [85-91] and carbocycles [92-97], which are also used as 
C5 synthon in the syntheses of isoquinolones by the intermolecular [5+1] cyclocondensation with primary amines.

As shown in Scheme 23, in the presence of $\mathrm{SiO}_{2}$, using an excess amount of $\mathrm{CuBr} \cdot \mathrm{SMe}_{2}$, the aerobic cyclocondensation of ortho-(1-alkynyl)benzaldehydes with benzyl amines or primary aliphatic amines affords 4-bromoisoquinolones [98]. $\mathrm{Cu}(\mathrm{OAc})_{2}$-catalyzed cyclocondensation of ortho-(1-alkynyl)benzaldehydes with aniline gives 2,3-diphenylisoquinolone in $63 \%$ yield [99].<smiles>[R]C#CC1=C(C(=O)C[18O][R])C=C[R]C=C1</smiles>

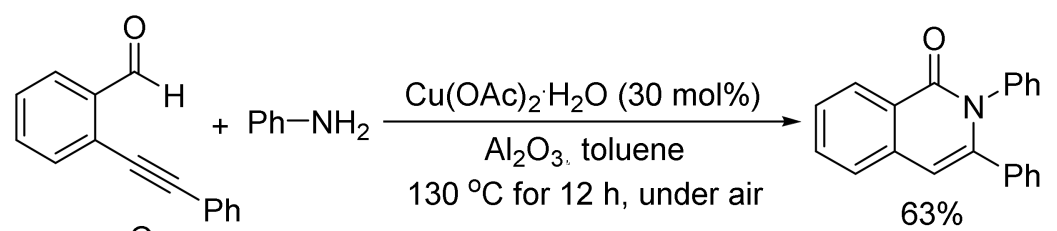

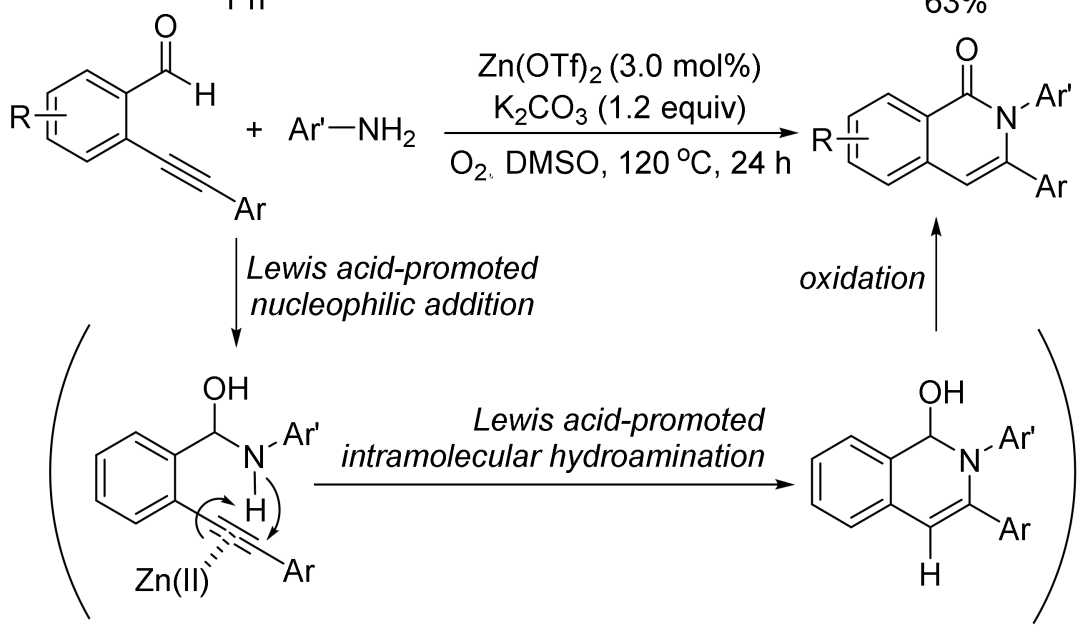

Scheme 23. Isoquinolone formation via [5 + 1] cyclocondensation of ortho-(1-alkynyl)-benzaldehydes with amines.

$\mathrm{Zn}(\mathrm{OTf})_{2}$ also shows catalytic activity for the aerobic cyclocondensation of ortho(1-alkynyl)benzaldehydes with arylamines to give $N$-arylated isoquinolones [100]. The proposed mechanism involves two well-known steps of nucleophilic addition of arylamines to aldehyde, and intramolecular hydroamination followed by oxidation reaction affording isoquinolone. $\mathrm{Zn}(\mathrm{OTf})_{2}$ plays an important role to promote both nucleophilic addition of arylamines and intramolecular hydroamination of carbon-carbon triple bond.

\section{Isoquinolone Syntheses via Other Intermolecular Annulations}

$\mathrm{A} \mathrm{Ni}(\mathrm{cod})_{2} /$ phosphine-catalyzed denitrogenative alkyne insertion reaction of 1,2,3benzotriazin-4(3H)-ones provides an alternatively efficient approach to substituted isoquinolones (Scheme 24) [101]. A wide-range isoquinolones can be obtained in high yields with the use of internal/terminal alkynes, including borylalkynes. This transformation can also be realized under visible-light irradiation with the assistance of a photocatalyst at room temperature [102]. 


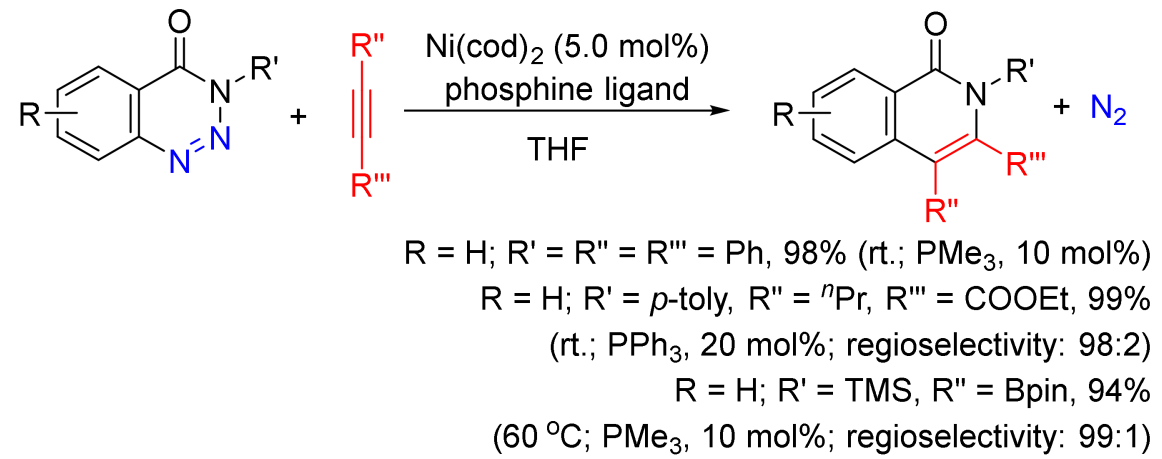

Scheme 24. Isoquinolone formation via nickel-catalyzed denitrogenative alkyne insertion of 1,2,3benzotriazin-4(3H)-ones.

In addition, the similar catalyst system can also catalyze a decarbonylative addition of phthalimides to internal alkynes to afford highly substituted isoquinolones (Scheme 25) [103]. The similar transformation can take place using $\mathrm{CoI}_{2} /$ phosphine $/ \mathrm{Ag}_{2} \mathrm{CO}_{3}$ [104], and $\mathrm{Rh}\left(\mathrm{PPh}_{3}\right)_{2}(\mathrm{CO}) \mathrm{Cl}$ as the catalyst systems [105].

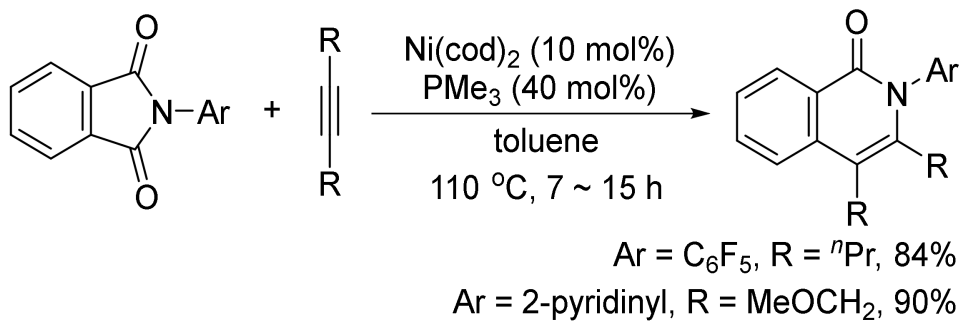

Scheme 25. Nickel-catalyzed decarbonylative addition of phthalimides to alkynes.

The isoquinolone skeleton can also be constructed by a $\mathrm{Pd}(\mathrm{OAc})_{2}$-catalyzed carbonylation/decarboxylation of diethyl(2-iodoaryl)malonates with imidoyl chlorides and $\mathrm{CO}$ in THF (Scheme 26) [106].

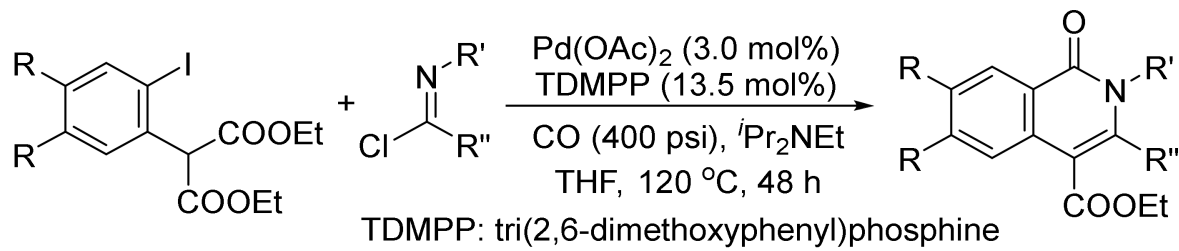

$$
\begin{array}{r}
\mathrm{R}=\mathrm{H}, \mathrm{R}^{\prime}=\mathrm{R}^{\prime \prime}=\mathrm{Ph}, 53 \% \\
\mathrm{R}=\mathrm{OMe}, \mathrm{R}^{\prime}={ }^{\prime} \mathrm{Pr}, \mathrm{R}^{\prime \prime}=\mathrm{Ph}, 70 \%
\end{array}
$$

Scheme 26. Palladium-catalyzed construction of isoquinolone ring by carbonylation/decarboxylation reaction.

The annulation reaction between benzocyclobutenols and isocyanates catalyzed by $[\mathrm{RhOH}(\mathrm{cod})]_{2}$ can also produce isoquinolone derivatives with excellent regioselectivity and functional-group tolerance (Scheme 27) [107]. The reactions give the first examples of formal amide fragment insertion into an aryl $\mathrm{C}-\mathrm{C}\left(s p^{3}\right)$ bond. 


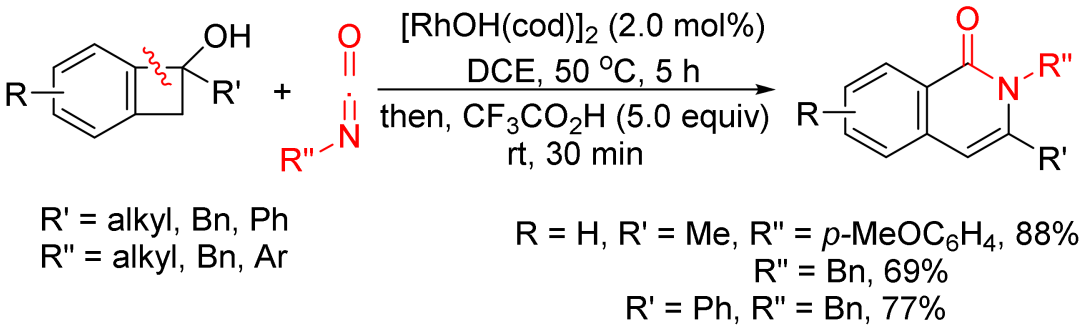

Scheme 27. Rhodium(I)-catalyzed cyclocondensation of benzocyclobutenols and isocyanates affording 3-substituted isoquinolone.

\section{Isoquinolone Syntheses via Intramolecular Annulation Reactions}

Isoquinolone syntheses via intramolecular annulation can be achieved starting from a variety of substrates. For example, the intramolecular cyclization of phosphorylated aromatic carboxamides promoted by base [108], palladium-catalyzed intramolecular cyclization of ortho-ethynylbenzamides [109], ortho-iodo-N-allenylbenzamides [110], palladiumcatalyzed, or base-promoted intramolecular cyclization of ortho-allenyl- $N$-substituted benzamides generated in situ [111].

When ortho-(2-substituted ethynyl)benzonitriles and $\mathrm{NaOMe}$ were refluxed in methanol for $16 \mathrm{~h}$, both isoindolones and isoquinolones formed in different ratios, depending on the nature of substituents. Substrates bearing the phenyl and thienyl group and stabilizing the $\alpha$-anion favor the 5-exo-pathway to give isoindolones, whereas pyridinyl and pyrazinyl groups can also stabilize the $\alpha$-anion, but the formation of a more stable intermediate by coordination of sodium with nitrogen atom leads to the formation of isoquinolones via 6-endo cyclization (Scheme 28) [112].

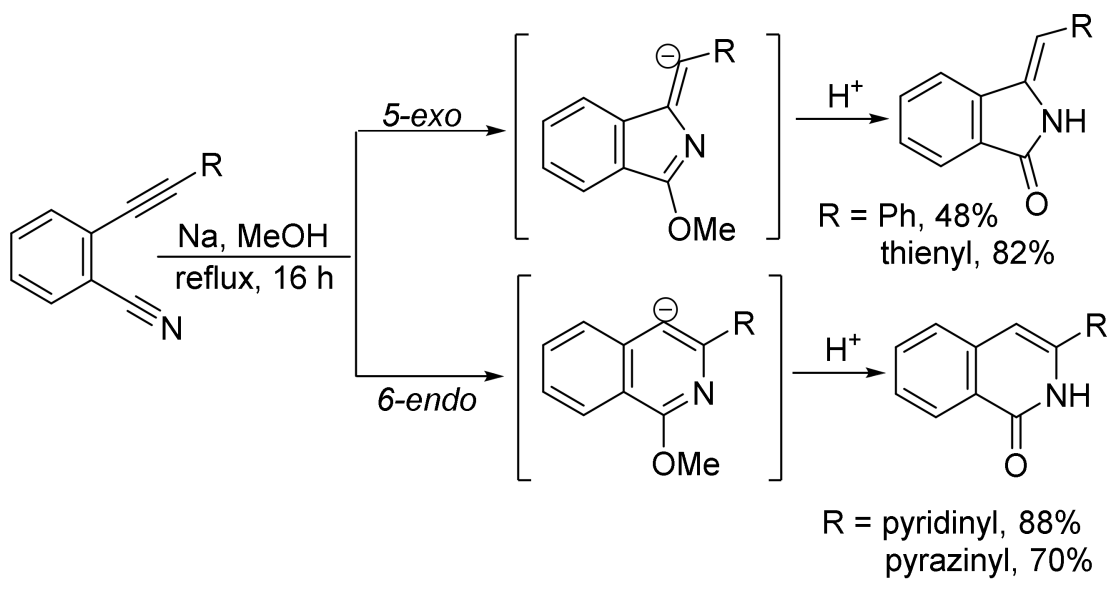

Scheme 28. Formation of isoindolones and isoquinolones.

In addition, in the presence of platinum complexes, the intramolecular cyclization of ortho-alkynylbenzonitriles in alcohols produces 3-substituted isoquinolones [113].

Treatment of ortho-iodobenzoyl azides with terminal alkynes in the presence of $\mathrm{Pd} / \mathrm{C}$, $\mathrm{PPh}_{3}$, and $\mathrm{CuI}$ in $\mathrm{EtOH}$ at $80^{\circ} \mathrm{C}$ under $\mathrm{N}_{2}$ afforded 3-substituted isoquinolones as the major products [114]. The formation of isoquinolones is proposed involving in situ generation of ortho-alkynyl benzoyl azides via Pd/C-mediated Sonogashira coupling followed by intramolecular acetylenic Schmidt reaction with denitrogenation (Scheme 29). Aliphatic terminal alkynes show high chemoselectivity to give the corresponding isoquinolones in good to high yields, whereas the use of aryl alkynes affords the desired products in low yield along with other side products. 


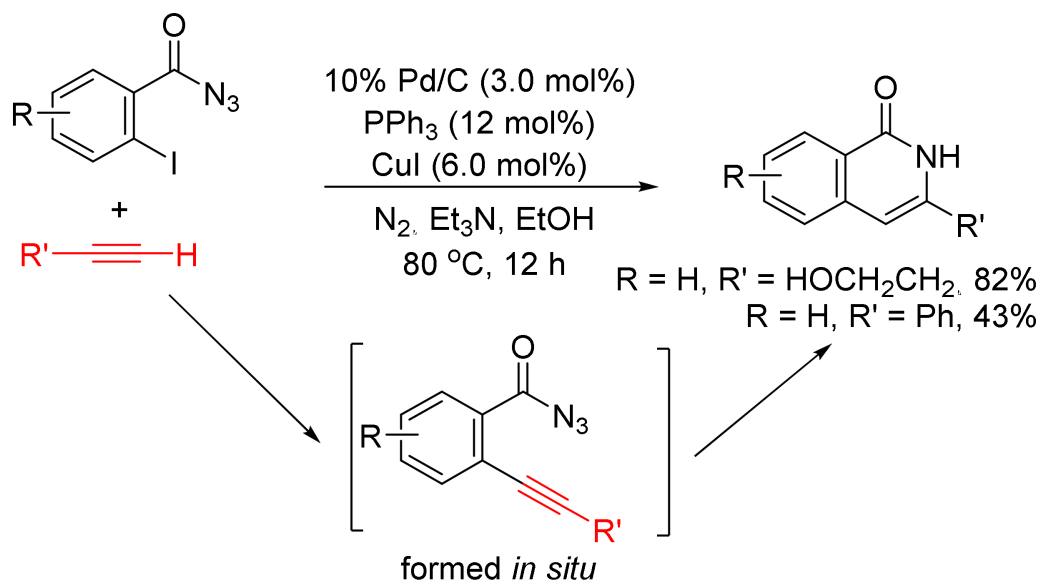

Scheme 29. Isoquinolone formation via intramolecular cyclization of ortho-alkynylbenzoyl azides.

In the presence of $\mathrm{H}_{2} \mathrm{O}, \mathrm{Cu}(\mathrm{OAc})_{2} \cdot \mathrm{H}_{2} \mathrm{O}$-catalyzed tandem cyclization reaction of 2-(1alkynyl)arylaldimines produces highly substituted isoquinolone derivatives (Scheme 30) [99].<smiles>[R]C#CC1=C(C=N[R])C#[R]=C1</smiles>

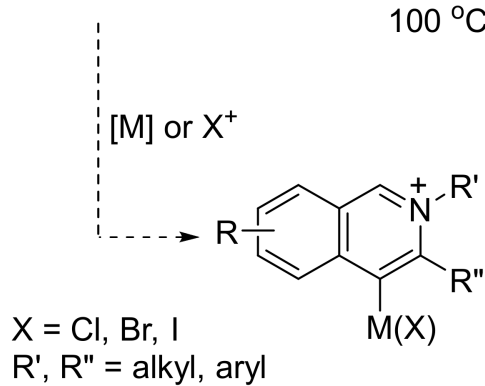

$\mathrm{R}^{\prime}, \mathrm{R}^{\prime \prime}=$ alkyl, aryl

$$
\begin{gathered}
\mathrm{Cu}(\mathrm{OAc})_{2} \cdot \mathrm{H}_{2} \mathrm{O}(30 \mathrm{~mol} \%) \\
\mathrm{H}_{2} \mathrm{O} \text { (5.0 equiv) } \\
\hline \text { with or without } \mathrm{NXS} \\
\text { air, toluene or } \mathrm{PhCl}
\end{gathered}
$$
$100{ }^{\circ} \mathrm{C} \sim 130{ }^{\circ} \mathrm{C}$<smiles>[R]C1=C([N])C2=C(C=C[R](O)C=C2)C(O)N1[R]</smiles>

Scheme 30. Isoquinolone formation by copper(II)-catalyzed tandem reactions of 2-(1-alkynyl) benzaldimines with water.

Moreover, 4-substituted isoquinolones can be prepared by a DBU-promoted isomerization of 4-(diarylmethylidene)-3,4-dihydroisoquinolinones, which are generated via the palladium-catalyzed tandem Heck-Suzuki coupling reactions of ortho-iodo- $N$-(prop-2ynyl)-benzamides with arylboronic acids under mild conditions (Scheme 31) [115].
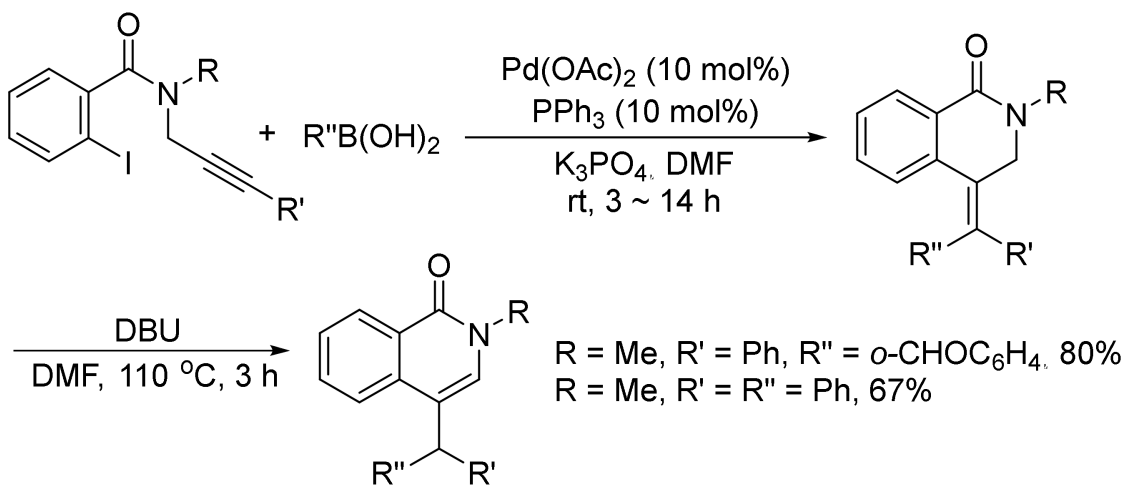

Scheme 31. Base-promoted isoquinolone synthesis via isomerization of 4-methylidene-3,4-dihydr oisoquinolinones. 
As shown in Scheme 8, the [4+2] cyclocondensation of $\mathrm{N}$-alkoxybenzamides with vinyl acetate gives 3,4-unsubstituted $\mathrm{N}-\mathrm{H}$ isoquinolones, and vinyl acetate is a good acetylene equivalent. The other approach to 3,4-unsubstituted $\mathrm{N}-\mathrm{H}$ isoquinolones is designed from the acid-promoted intramolecular cyclization of ortho-vinyl ether benzamides, which are pre-prepared by Suzuki cross-coupling reactions of the corresponding pinacol borate esters with ortho-bromobenzamides (Scheme 32 (a)) [116]. Using trifluoroacetic acid (TFA) as a solvent, the intramolecular cyclization occurs to form isoquinolone ring with $t$-butyl group removed under the strong acidic conditions and microwave irradiation. A similar procedure was reported under mild conditions promoted by $\mathrm{HCl}$ in dioxane to give $\mathrm{N}$-substituted 3,4-unsubstituted isoquinolones (Scheme 32 (b)) [117].

(a)<smiles>CCCC[R]1ccc(C(=O)NCC)c(/C=C/OCC)c1</smiles><smiles>O=c1[nH]ccc2cc[R]cc12</smiles>

3,4-unsubstituted

(b)

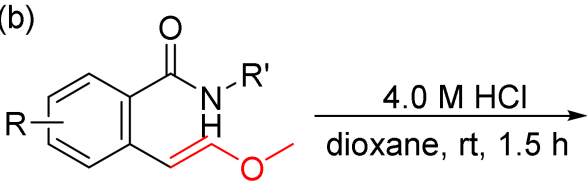
$\mathrm{N}-\mathrm{H}$ isoquinolones

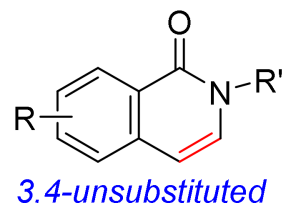

Scheme 32. 3,4-Unsubstituted isoquinolones via acid-promoted intramolecular cyclization of orthovinyl ether benzamides.

\section{Polycyclic-Fused Isoquinolone Formation via Alkyne Annulation}

Annulation protocols under different conditions have been extensively studied for one-pot and efficient approach to polycyclic-fused isoquinolones [118-121]. Transition metal-catalyzed procedures focus on the use of $\left[\mathrm{Cp}^{*} \mathrm{RhCl}_{2}\right] 2$, $\left[\mathrm{RuCl}_{2}(p-c y m e n e)\right]_{2}$, and $\mathrm{CuCl}$ catalysts, through the intermolecular annulation of alkynes with benzamides and intramolecular annulation of alkyne-tethered benzamides, which are reviewed in this section.

In 2010, $\mathrm{Li}$ and coworker reported a $\left[\mathrm{Cp} * \mathrm{RhCl}_{2}\right]_{2}$-catalyzed double oxidative cyclocoupling of primary benzamides with two molecules of alkynes affording tetracyclic isoquinolones resulting from the formation of two $\mathrm{C}-\mathrm{N}$ bonds and two $\mathrm{C}-\mathrm{C}$ bonds simultaneously with the use of $\mathrm{Ag}_{2} \mathrm{CO}_{3}$ as an oxidant (Scheme 33) [52], which is similar to the use of $\mathrm{Cu}(\mathrm{OAc})_{2} \cdot 2 \mathrm{H}_{2} \mathrm{O}$ as the oxidant as shown in Scheme 13. In the presence of $\mathrm{CsOAc}$, the same catalyst also catalyzes the cyclization of $\mathrm{N}$-(pivaloyloxy)benzamide with cyclohexadienone-containing 1,6-enynes, providing one-pot synthesis of tetracyclic isoquinolones under mild conditions (Scheme 34) [122].

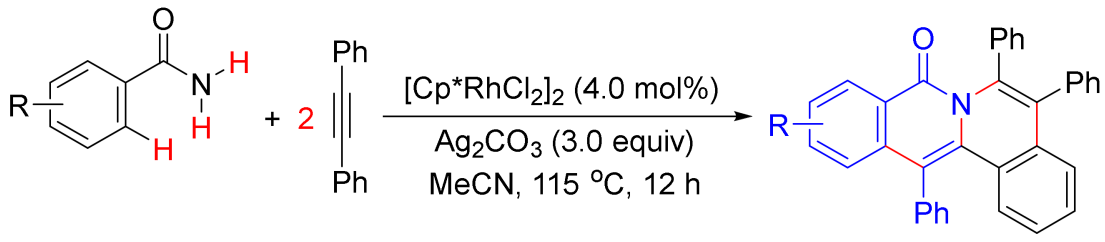

$\mathrm{R}=\mathrm{Me}, \mathrm{MeO}, \mathrm{F}, \mathrm{NO}_{2}, \mathrm{CN}$

Scheme 33. Tetracyclic isoquinolone formation by $\mathrm{Rh}(\mathrm{III})$-catalyzed double oxidative cyclocoupling between primary benzamides and alkynes. 


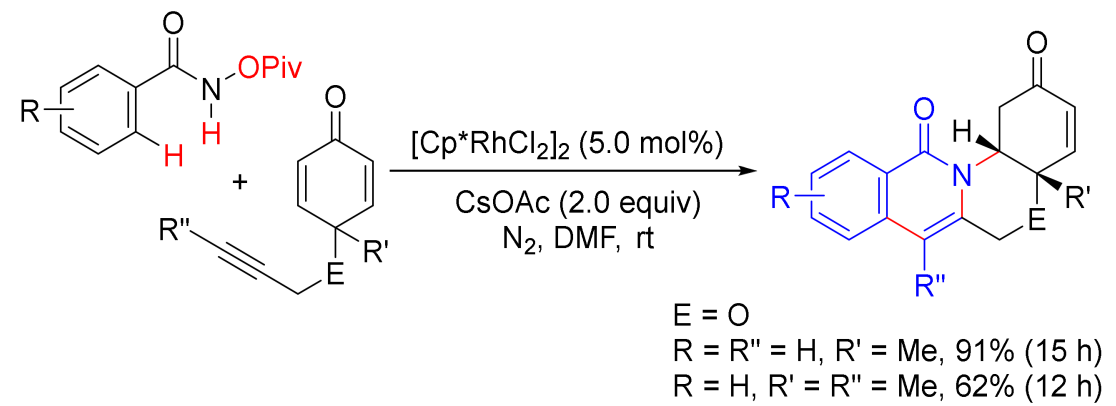

Scheme 34. Tetracyclic isoquinolone formation by $\mathrm{Rh}(\mathrm{III})$-catalyzed cyclization of $\mathrm{N}$-(pivaloyloxy) benzamide with 1,6-enynes.

In the presence of additive and/or oxidant, $\left[\mathrm{Cp} * \mathrm{RhCl}_{2}\right]_{2}$-catalyzed formation of other polycyclic-fused isoquinolones is shown in Figure 2. Furthermore, 2,3-Dihydropyrrolo [1,2-b] isoquinolin-5(1H)-ones $(n=1)$ [123], and isoindolo[2,1-b]isoquinolin-5(7H)-ones $(\mathrm{n}=1)$ [124] can be prepared by intramolecular annulations of alkyne tethered benzamides, and the latter approach is used in the synthesis of nitrogen-containing natural products such as rosettacin and oxypalmatime. The intermolecular cascade annulation between $\mathrm{N}$-pivaloyloxy benzamides and ortho-alkynylbenzaldehydes can give 7-hydroxyisoindolo[2,1-b]-isoquinolin-5(7H)-ones and also afford the convenient intermediates for access to rosettacin $[125,126]$. In addition, the intermolecular cyclization of $N$-pivaloyloxy benzamides with conjugated enynones affords pyrrolo[1,2-b]isoquinolin-5(3H)-ones [127]. All the formed polycyclic isoquinolones are not easily available to be synthesized by multi-step traditional organic transformation.<smiles>[R]Cc1c2n(c(=O)c3cc[R]cc13)C[C@H](N)C2</smiles><smiles>[R]c1c2cc[R]ccc2c(=O)n2c(=O)n(C)c12</smiles><smiles>[R]c1cccc2c(=O)n3c(c([R])c12)-c1ccccc1C3O</smiles><smiles>CC(=O)C1Cc2c(-c3ccccc3)c3ccccc3c(=O)n2C1(C)O</smiles>

Figure 2. Polycyclic fused isoquinolones.

As described in Scheme 7, [Cp* $\left.\mathrm{RhCl}_{2}\right]_{2} / \mathrm{CsOAc}$-catalyzed intramolecular reaction of alkyne-tethered $\mathrm{N}$-alkoxybenzamides leads to 3-hydroxyalkyl-substituted $\mathrm{N}-\mathrm{H}$ isoquinolones by selective $\mathrm{C}-\mathrm{H} / \mathrm{N}-\mathrm{O}$ activation [31]. However, $\mathrm{CuCl}$-catalyzed aerobic oxidative radical cascade annulations of the similar substrates give isoxazolidine/1,2oxazinane-fused isoquinolones, and $\mathrm{N}-\mathrm{O}$ bond is untouched (Scheme 35) [128]. This transformation features air as the environment-friendly oxidant and has the merits of a cheap catalyst, broad substrates scope, high atom economy, and simple operation.

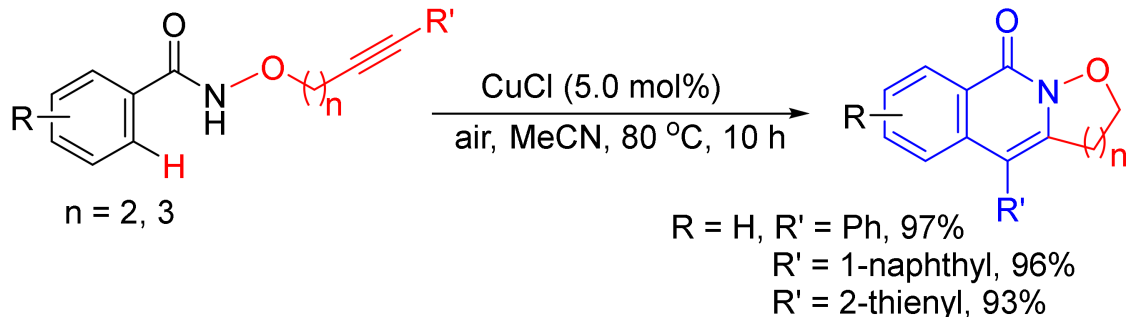

Scheme 35. CuCl-catalyzed synthesis of isoxazolidine-fused isoquinolones. 
Very recently, the formation of isoxazolidine-fused isoquinolones starting from alkynetethered $\mathrm{N}$-alkoxybenzamides has been reported by electrochemical-oxidation-induced [129] and $\mathrm{PhI}(\mathrm{OAc})_{2}$-mediated [130] intramolecular annulations.

$\left[\mathrm{Ru}(p \text {-cymene }) \mathrm{Cl}_{2}\right]_{2}$ not only shows the catalytic activity for the construction of isoquinolone ring as described-above but also has been employed as catalyst in the formation of polycyclic-fused isoquinolones, such as tetracyclic isoquinolones [131] and spiro-fusedisoquinolones [132] (Figure 3).<smiles>[R][C@]12Cc3c([Al])c4ccccc4c(=O)n3[C@@](O)(CCC1=O)C2</smiles>

[132]<smiles>O=C1CC2(c3ccccc31)c1ccccc1C(=O)N2C1=C(c2ccccc2)c2cccc(O)c2C1=O</smiles>

[133]

Figure 3. Ruthenium(II)-catalyzed syntheses of polycyclic fused isoquinolones.

\section{Conclusions}

This mini-review summaries the representative reports on the syntheses of isoquinolones and polycyclic-fused isoquinolones by annulation protocols in one-pot manner, which show atom- and step-economy. The new trend of developing annulation reactions in the synthesis of cyclic compounds has recently been diversified; in addition to transition-metal catalysis, the electrocatalysis [133-137] and photocatalysis [138-141] with or without combination of metal-catalyzed catalysis have also become the novel and elegant methods in annulation synthesis. The construction of isoquinolone ring under these conditions has also been developed via [4 +2] annulation of benzamides with terminal/internal alkynes [142-147].

Funding: The research works published by author and cited here were funded by the National Natural Science Foundation of China (Nos. 21473097, 21673124, and 21972072).

Conflicts of Interest: The authors declare no conflict of interest.

\section{References}

1. Nakamura, I.; Yamamoto, Y. Transition-metal-catalyzed reactions in heterocyclic synthesis. Chem. Rev. 2004, 104, 2127-2198. [CrossRef] [PubMed]

2. Zeni, G.; Larock, R.C. Synthesis of heterocycles via palladium $\pi$-olefin and $\pi$-alkyne Chemistry. Chem. Rev. 2004, 104, 2285-2309. [CrossRef] [PubMed]

3. Hua, R.; Abrenica, M.V.A.; Wang, P. Cycloaddition of alkynes: Atom-economic protocols for constructing six-membered cycles. Curr. Org. Chem. 2011, 15, 712-729. [CrossRef]

4. Gulevich, A.V.; Dudnik, A.S.; Chernyak, N.; Gevorgyan, V. Transition metal-mediated synthesis of monocyclic aromatic heterocycles. Chem. Rev. 2013, 113, 3084-3213. [CrossRef]

5. Nizami, T.A.; Hua, R. Cycloaddition of 1,3-butadiynes: Efficient synthesis of carbo- and heterocycles. Molecules 2014, 19, 13788-13802. [CrossRef]

6. Fang, G.; Bi, X. Silver-catalyzed reactions of alkynes: Recent advances. Chem. Soc. Rev. 2015, 44, 8124-8173. [CrossRef]

7. Huang, M.-H.; Hao, W.-J.; Li, G.; Tu, S.-J.; Jiang, B. Recent advances in radical transformations of internal alkynes. Chem. Commun. 2018, 54, 10791-10811. [CrossRef]

8. Zheng, L.; Hua, R. C-H activation and alkyne annulation via automatic or intrinsic directing groups: Towards high step economy. Chem. Rec. 2018, 18, 556-569. [CrossRef]

9. Hua, R.; Nizami, T.A. Synthesis of heterocycles by using propargyl compounds as versatile synthons. Mini Rev. Org. Chem. 2018, 15, 198-207. [CrossRef]

10. Zheng, L.; Hua, R. Recent advances in construction of polycyclic natural product scaffolds via one-pot reactions involving alkyne annulation. Front. Chem. 2020, 8, 580355. [CrossRef]

11. Strumberg, D.; Pommier, Y.; Paull, K.; Jayaraman, M.; Nagafuji, P.; Cushman, M. Synthesis of cytotoxic indenoisoquinoline topoisomerase I poisons. J. Med. Chem. 1999, 42, 446-457. [CrossRef]

12. Glushkov, V.A.; Shklyaev, Y.V. Synthesis of 1(2H)-isoquinolones. Chem. Heterocycl. Compd. 2001, 37, 663-687. [CrossRef] 
13. Cappelli, A.; Mohr, G.P.; Giuliani, G.; Galeazzi, S.; Anzini, M.; Mennuni, L.; Ferrari, F.; Makovec, F.; Kleinrath, E.M.; Langer, T.; et al. Further studies on imidazo[4,5-b]pyridine AT1 angiotensin II receptor antagonists. Effects of the transformation of the 4-phenylquinoline backbone into 4-phenylisoquinolinone or 1-phenylindene scaffolds. J. Med. Chem. 2006, 49, 6451-6464. [CrossRef]

14. Li, B.; Feng, H.; Wang, N.; Ma, J.; Song, H.; Xu, S.; Wang, B. Ruthenium-catalyzed oxidative coupling/cyclization of isoquinolones with alkynes through $\mathrm{C}-\mathrm{H} / \mathrm{N}-\mathrm{H}$ activation: Mechanism study and synthesis of dibenzo[ $[a, g]$ quinolizin-8-one derivatives. Chem. Eur. J. 2012, 18, 12873-12879. [CrossRef]

15. Cobas, A.; Guitián, E.; Castedo, L. Synthesis of 3-phenylisoquinolones by reaction of simple pyrroline-2,3-diones with benzyne. New mechanistic considerations. J. Org. Chem. 1993, 58, 3113-3117. [CrossRef]

16. Fisher, L.E.; Muchowski, J.M.; Clark, R.D. Heteroatom-directed metalation. Lithiation of N-propenylbenzamides and N-propenylo-toluamides. Novel routes to ortho-substituted primary benzamide derivatives and $\mathrm{N}$-unsubstituted isoquinolin- $1(2 \mathrm{H})$-ones. $J$. Org. Chem. 1992, 57, 2700-2705. [CrossRef]

17. Davis, S.E.; Church, A.C.; Griffith, C.L.M.; Beam, C.F. The preparation of substituted 1(2H)-isoquinolinones from dilithiated 2-methyl-N-arylbenzamides, 2-methyl-N-(arylmethyl)benzamides, or 2-methylbenzoic acid, 2,2-dimethylhydrazide. Synth. Commun. 1997, 27, 2961-2969. [CrossRef]

18. Snow, R.J.; Butz, T.; Hammach, A.; Kapadia, S.; Morwick, T.M.; Prokopowicz, A.S., III; Takahashi, H.; Tan, J.D.; Tschantz, M.A.; Wang, X.-J. Isoquinolinone synthesis by $\mathrm{S}_{N}$ Ar reaction: A versatile route to imidazo[4,5- $h$ ] isoquinolin-9-ones. Tetrahedron Lett. 2002, 43, 7553-7556. [CrossRef]

19. Omer, H.M.; Liu, P. Computational study of the Ni-catalyzed C-H oxidative cycloaddition of aromatic amides with alkynes. ACS Omega 2019, 4, 5209-5220. [CrossRef]

20. Liu, C.-C.; Parthasarathy, K.; Cheng, C.-H. Synthesis of highly substituted isoquinolone derivatives by nickel-catalyzed annulation of 2-halobenzamides with alkynes. Org. Lett. 2010, 12, 3518-3521. [CrossRef]

21. Weng, W.-Z.; Xie, J.; Zhang, B. Mild and efficient synthesis of indoles and isoquinolones via a nickel-catalyzed Larock-type heteroannulation reaction. Org. Biomol. Chem. 2018, 16, 3983-3988. [CrossRef]

22. Nohira, I.; Liu, S.; Bai, R.; Lan, Y.; Chatani, N. Nickel-catalyzed C-F/N-H annulation of aromatic amides with alkynes: Activation of C-F bonds under mild reaction conditions. J. Am. Chem. Soc. 2020, 142, 17306-17311. [CrossRef]

23. Xie, H.; Xing, Q.; Shan, Z.; Xiao, F.; Deng, G.-J. Nickel-catalyzed annulation of $o$-haloarylamidines with aryl acetylenes: Synthesis of isoquinolone and 1-aminoisoquinoline Derivatives. Adv. Synth. Catal. 2019, 361, 1896-1901. [CrossRef]

24. Wang, F.; Liu, H.; Fu, H.; Jiang, Y.; Zhao, Y. An efficient one-pot copper-catalyzed approach to isoquinolin-1(2H)-one derivatives Org. Lett. 2009, 11, 2469-2472. [CrossRef]

25. Thansandote, P.; Hulcoop, D.G.; Langer, M.; Lautens, M. Palladium-catalyzed annulation of haloanilines and halobenzamides using norbornadiene as an acetylene synthon: A route to functionalized indolines, isoquinolinones, and indoles. J. Org. Chem. 2009, 74, 1673-1678. [CrossRef]

26. Liu, Y.; Zeng, R.; Pan, J.; Zou, J. Copper(II)-catalyzed synthesis of $N$-substituted-3-amino-4-cyano-isoquinoline-1(2H)-ones by the reaction of $N$-substituted-2-iodobenzamides with malononitrile. Chin. J. Chem. 2014, 32, 883-888. [CrossRef]

27. Shi, Y.; Zhu, X.; Mao, H.; Hu, H.; Zhu, C.; Cheng, Y. Synthesis of functionalized isoquinolin-1(2H)-ones by copper-catalyzed $\alpha$-arylation of ketones with 2-halobenzamides. Chem. Eur. J. 2013, 19, 11553-11557. [CrossRef]

28. Mayo, M.S.; Yu, X.; Feng, X.; Yamamoto, Y.; Bao, M. Isoquinolone synthesis through $S_{N} A r$ reaction of 2-halobenzonitriles with ketones followed by cyclization. J. Org. Chem. 2015, 80, 3998-4002. [CrossRef]

29. Guimond, N.; Gouliaras, C.; Fagnou, K. Rhodium(III)-catalyzed isoquinolone synthesis: The N-O bond as a handle for C-N bond formation and catalyst turnover. J. Am. Chem. Soc. 2010, 132, 6908-6909. [CrossRef]

30. Guimond, N.; Gorelsky, S.I.; Fagnou, K. Rhodium(III)-catalyzed heterocycle synthesis using an internal oxidant: Improved reactivity and mechanistic studies. J. Am. Chem. Soc. 2011, 133, 6449-6457. [CrossRef]

31. Xu, X.; Liu, Y.; Park, C.-M. Rhodium(III)-catalyzed intramolecular annulation through C-H activation: Total synthesis of $( \pm)$-Antofine, $( \pm)$-Septicine, $( \pm)$-Tylophorine, and Rosettacin. Angew. Chem. Int. Ed. 2012, 51, 9372-9376. [CrossRef] [PubMed]

32. Webb, N.J.; Marsden, S.P.; Raw, S.A. Rhodium(III)-catalyzed C-H activation/annulation with vinyl esters as an acetylene equivalent. Org. Lett. 2014, 16, 4718-4721. [CrossRef] [PubMed]

33. Hyster, T.K.; Rovis, T. Rhodium(III)-catalyzed C-H activation mediated synthesis of isoquinolones from amides and cyclopropenes. Synlett 2013, 24, 1842-1844. [CrossRef] [PubMed]

34. Wang, H.; Glorius, F. Mild rhodium(III)-catalyzed C-H activation and intermolecular annulation with allenes. Angew. Chem. Int. Ed. 2012, 51, 7318-7322. [CrossRef]

35. Sun, R.; Yang, X.; Li, Q.; Xu, K.; Tang, J.; Zheng, X.; Yuan, M.; Fu, H.; Li, R.; Chen, H. Divergent synthesis of isoquinolone and isocoumarin derivatives by the annulation of benzoic acid with N-vinyl amide. Org. Lett. 2019, 21, 9425-9429. [CrossRef]

36. Coles-Taylor, B.L.; McCallum, M.S.; Lee, J.S.; Michel, B.W. Accessing 4-oxy-substituted isoquinolinones via C-H activation and regioselective migratory insertion with electronically biased ynol ethers. Org. Biomol. Chem. 2018, 16, 8639-8646. [CrossRef]

37. Li, B.; Feng, H.; Xu, S.; Wang, B. Ruthenium-catalyzed isoquinolone synthesis through C-H activation using an oxidizing directing group. Chem. Eur. J. 2011, 17, 12573-12577. [CrossRef]

38. Guntreddi, T.; Shankar, M.; Kommu, N.; Sahoo, A.K. Construction of pyranoisoquinolines via Ru(II)-catalyzed unsymmetrical double annulation of $\mathrm{N}$-methoxybenzamides with unactivated alkynes. J. Org. Chem. 2019, 84, 13033-13044. [CrossRef] 
39. Ackermann, L.; Fenner, S. Ruthenium-catalyzed C-H/N-O bond functionalization: Green isoquinolone syntheses in water. Org. Lett. 2011, 13, 6548-6551. [CrossRef]

40. Krieger, J.-P.; Ricci, G.; Lesuisse, D.; Meyer, C.; Cossy, J. Harnessing C-H activation of benzhydroxamates as a macrocyclization strategy: Synthesis of structurally diverse macrocyclic isoquinolones. Chem. Eur. J. 2016, 22, 13469-13473. [CrossRef]

41. Yang, J.; Wu, L.; Xu, H.; Gao, H.; Zhou, Z.; Yi, W. Redox-neutral [4 + 2] annulation of N-methoxybenzamides with alkynes enabled by an osmium(II)/HOAc catalytic system. Org. Lett. 2019, 21, 9904-9908. [CrossRef]

42. Liu, M.; Niu, J.-L.; Yang, D.; Song, M.-P. Development of a traceless directing group: Cp*-free cobalt-catalyzed C-H activation/annulations to access isoquinolinones. J. Org. Chem. 2020, 85, 4067-4078. [CrossRef]

43. Huang, H.; Nakanowatari, S.; Ackermann, L. Selectivity control in ruthenium(II)-catalyzed C-H/N-O activation with alkynyl bromides. Org. Lett. 2017, 19, 4620-4623. [CrossRef]

44. Song, L.; Zhang, X.; Tang, X.; Van Meervelt, L.; Van der Eycken, J.; Harvey, J.N.; Van der Eycken, E.V. Ruthenium-catalyzed cascade $\mathrm{C}-\mathrm{H}$ activation/annulation of $\mathrm{N}$-alkoxybenzamides: Reaction development and mechanistic insight. Chem. Sci. 2020, 11, 11562-11569. [CrossRef]

45. Yu, B.; Chen, Y.; Hong, M.; Duan, P.; Gan, S.; Chao, H.; Zhao, Z.; Zhao, J. Rhodium-catalyzed C-H activation of hydrazines leads to isoquinolones with tunable aggregation-induced emission properties. Chem. Commun. 2015, 51, 14365-14368. [CrossRef]

46. Zhu, H.; Zhuang, R.; Zheng, W.; Fu, L.; Zhao, Y.; Tu, L.; Chai, Y.; Zeng, L.; Zhang, C.; Zhang, J. Synthesis of isoquinolone via rhodium(III)-catalyzed C-H activation with 1,4,2-dioxazol-5-ones as oxidizing directing group. Tetrahedron 2019, 75, 3108-3112 [CrossRef]

47. Li, X.; Zhang, R.; Qi, Y.; Zhao, Q.; Yao, T. Rhodium(III)-catalyzed C-H activation/annulation of N-iminopyridinium ylides with alkynes and diazo compounds. Org. Chem. Front. 2021, 8, 1190-1196. [CrossRef]

48. Yang, Z.; Jie, L.; Yao, Z.; Yang, Z.; Cui, X. Rhodium (III)-catalyzed synthesis of N-(2-acetoxyalkyl)isoquinolones from oxazolines and alkynes through C-N bond formation and ring-opening. Adv. Synth. Catal. 2019, 361, 214-218. [CrossRef]

49. Yu, X.; Chen, K.; Guo, S.; Shi, P.; Song, C.; Zhu, J. Direct access to cobaltacycles via C-H activation: N-Chloroamide-enabled room-temperature synthesis of heterocycles. Org. Lett. 2017, 19, 5348-5351. [CrossRef]

50. Mochida, S.; Umeda, N.; Hirano, K.; Satoh, T.; Miura, M. Rhodium-catalyzed oxidative coupling/cyclization of benzamides with alkynes via C-H bond cleavage. Chem. Lett. 2010, 39, 744-746. [CrossRef]

51. Hyster, T.K.; Rovis, T. Rhodium-catalyzed oxidative cycloaddition of benzamides and alkynes via C-H/N-H activation. J. Am. Chem. Soc. 2010, 132, 10565-10569. [CrossRef] [PubMed]

52. Song, G.; Chen, D.; Pan, C.-L.; Crabtree, R.H.; Li, X. Rh-catalyzed oxidative coupling between primary and secondary benzamides and alkynes: Synthesis of polycyclic amides. J. Org. Chem. 2010, 75, 7487-7490. [CrossRef]

53. Upadhyay, N.S.; Thorat, V.H.; Sato, R.; Annamalai, P.; Chuang, S.-C.; Cheng, C.-H. Synthesis of isoquinolones via Rh-catalyzed C-H activation of substituted benzamides using air as the sole oxidant in water. Green Chem. 2017, 19, 3219-3224. [CrossRef]

54. Ackermann, L.; Lygin, A.V.; Hofmann, N. Ruthenium-catalyzed oxidative annulation by cleavage of C-H/N-H bonds. Angew. Chem. Int. Ed. 2011, 50, 6379-6382. [CrossRef]

55. Allu, S.; Swamy, K.C.K. Ruthenium-catalyzed synthesis of isoquinolones with 8-aminoquinoline as a bidentate directing group in C-H functionalization. J. Org. Chem. 2014, 79, 3963-3972. [CrossRef]

56. Zhong, H.; Yang, D.; Wang, S.; Huang, J. Pd-catalyzed synthesis of isoquinolinones and analogues via C-H and N-H bonds double activation. Chem. Commun. 2012, 48, 3236-3238. [CrossRef]

57. Lu, S.; Lin, Y.; Zhong, H.; Zhao, K.; Huang, J. A practical one-pot procedure for the synthesis of N-H isoquinolones. Tetrahedron Lett. 2013, 54, 2001-2005. [CrossRef]

58. Zhang, N.; Li, B.; Zhong, H.; Huang, J. Synthesis of $\mathrm{N}$-alkyl and $\mathrm{N}$-aryl isoquinolones and derivatives via Pd-catalyzed C-H activation and cyclization reactions. Org. Biomol. Chem. 2012, 10, 9429-9439. [CrossRef] [PubMed]

59. Peng, X.; Wang, W.; Jiang, C.; Sun, D.; Xu, Z.; Tung, C.-H. Strain-promoted oxidative annulation of arynes and cyclooctynes with benzamides: Palladium-catalyzed C-H/N-H activation for the synthesis of N-heterocycles. Org. Lett. 2014, 16, 5354-5357. [CrossRef] [PubMed]

60. Zhao, J.; Li, H.; Li, P.; Wang, L. Annulation of benzamides with arynes using palladium with photoredox dual catalysis. J. Org. Chem. 2019, 84, 9007-9016. [CrossRef]

61. Shiota, H.; Ano, Y.; Aihara, Y.; Fukumoto, Y.; Chatani, N. Nickel-catalyzed chelation-assisted transformations involving ortho- C-H bond activation: Regioselective oxidative cycloaddition of aromatic amides to alkynes. J. Am. Chem. Soc. 2011, 133, 14952-14955. [CrossRef]

62. Obata, A.; Ano, Y.; Chatani, N. Nickel-catalyzed C-H/N-H annulation of aromatic amides with alkynes in the absence of a specific chelation system. Chem. Sci. 2017, 8, 6650-6655. [CrossRef]

63. Matsubara, T.; Ilies, L.; Nakamura, E. Oxidative C-H activation approach to pyridone and isoquinolone through an iron-catalyzed coupling of amides with alkynes. Chem. Asian J. 2016, 11, 380-384. [CrossRef] [PubMed]

64. Sharma, N.; Saha, R.; Parveen, N.; Sekar, G. Palladium-nanoparticles-catalyzed oxidative annulation of benzamides with alkynes for the synthesis of isoquinolones. Adv. Synth. Catal. 2017, 359, 1947-1958. [CrossRef]

65. Shu, Z.; Li, W.; Wang, B. Pd/C-catalyzed synthesis of isoquinolones through C-H activation. ChemCatChem 2015, 7, 605-608. [CrossRef] 
66. Shu, Z.; Guo, Y.; Li, W.; Wang, B. Pd/C-catalyzed synthesis of N-aryl and N-alkyl isoquinolones via C-H/N-H activation. Catal. Today 2017, 297, 292-297. [CrossRef]

67. Hao, X.-Q.; Du, C.; Zhu, X.; Li, P.-X.; Zhang, J.-H.; Niu, J.-L.; Song, M.-P. Cobalt(II)-catalyzed decarboxylative C-H activation/annulations cascades: Regioselective access to isoquinolones and isoindolinones. Org. Lett. 2016, 18, 3610-3613. [CrossRef]

68. Lin, C.; Shen, L. Co-catalyzed ortho-C-H functionalization/annulation of arenes and alkenes with alkynylsilanes: Access to isoquinolone and pyridine motifs. RSC Adv. 2019, 9, 30650-30654. [CrossRef]

69. Manna, S.; Antonchick, A.P. Organocatalytic oxidative annulation of benzamide derivatives with alkynes. Angew. Chem. Int. Ed. 2014, 53, 7324-7327. [CrossRef]

70. Chen, Z.-W.; Zhu, Y.-Z.; Ou, J.-W.; Wang, Y.-P.; Zheng, J.-Y. Metal-free iodine(III)-promoted synthesis of isoquinolones. J. Org. Chem. 2014, 79, 10988-10998. [CrossRef]

71. Sagara, P.S.; Siril, P.F.; Ravikumar, P.C. N-Amino-7-azaindole as the $N, N^{\prime}$-bidentate directing group: Ruthenium-catalyzed oxidative annulation of $\mathrm{N}$-(7-azaindole)benzamides with alkynes via C-H bond activation. J. Org. Chem. 2019, 84, 12314-12323. [CrossRef] [PubMed]

72. Yu, D.-G.; de Azambuja, F.; Glorius, F. $\alpha$-MsO/TsO/Cl Ketones as oxidized alkyne equivalents: Redox-neutral rhodium(III)catalyzed C-H activation for the synthesis of N-heterocycles. Angew. Chem. Int. Ed. 2014, 53, 2754-2758. [CrossRef] [PubMed]

73. Xie, C.; Dai, Z.; Niu, Y.; Ma, C. Cascade one-pot method to synthesize isoquinolin-1(2H)-ones with $\alpha$-bromo ketones and benzamides via Pd-catalyzed C-H activation. J. Org. Chem. 2018, 83, 2317-2323. [CrossRef]

74. Huang, J.-R.; Bolm, C. Microwave-assisted synthesis of heterocycles by rhodium(III)-catalyzed annulation of $N$-methoxyamides with $\alpha$-chloroaldehydes. Angew. Chem. Int. Ed. 2017, 56, 15921-15925. [CrossRef]

75. Barday, M.; Janot, C.; Halcovitch, N.R.; Muir, J.; Aïssa, C. Cross-coupling of $\alpha$-carbonyl sulfoxonium ylides with C-H bonds. Angew. Chem. Int. Ed. 2017, 56, 1311-13121. [CrossRef]

76. Xu, Y.; Zheng, G.; Yang, X.; Li, X. Rhodium(III)-catalyzed chemodivergent annulations between N-methoxybenzamides and sulfoxonium ylides via C-H activation. Chem. Commun. 2018, 54, 670-673. [CrossRef]

77. Wang, H.; Cao, F.; Gao, W.; Wang, X.; Yang, Y.; Shi, T.; Wang, Z. Pd(II)-catalyzed annulation reactions of epoxides with benzamides to synthesize isoquinolones. Org. Lett. 2021, 23, 863-868. [CrossRef]

78. Xu, G.-D.; Huang, Z.-Z. A cascade dehydrogenative cross-coupling/annulation reaction of benzamides with $\beta$-keto esters for the synthesis of isoquinolinone derivatives. Org. Lett. 2017, 19, 6265-6267. [CrossRef]

79. Shi, L.; Yu, K.; Wang, B. Regioselective synthesis of multisubstituted isoquinolones and pyridones via Rh(III)-catalyzed annulation reactions. Chem. Commun. 2015, 51, 17277-17280. [CrossRef]

80. Wu, Y.; Sun, P.; Zhang, K.; Yang, T.; Yao, H.; Lin, A. Rh(III)-catalyzed redox-neutral annulation of primary benzamides with diazo compounds: Approach to isoquinolinones. J. Org. Chem. 2016, 81, 2166-2173. [CrossRef]

81. Li, Z.; Wu, L.; Chang, B.; Lu, P.; Wang, Y. Rh(III)-catalyzed synthesis of 3-amino-4-arylisoquinolinones from 4-diazoisochroman-3imines and N-methoxybenzamides. Org. Lett. 2019, 21, 1497-1501. [CrossRef]

82. Thrimurtulu, N.; Dey, A.; Maiti, D.; Volla, C.M.R. Cobalt-catalyzed $s p^{2}-\mathrm{C}-\mathrm{H}$ activation: Intermolecular heterocyclization with allenes at room temperature. Angew. Chem. Int. Ed. 2016, 55, 12361-12365. [CrossRef]

83. Boobalan, R.; Kuppusamy, R.; Santhoshkumar, R.; Gandeepan, P.; Cheng, C.-H. Access to isoquinolin-1(2H)-ones and pyridones by cobalt-catalyzed oxidative annulation of amides with allenes. ChemCatChem 2017, 9, 273-277. [CrossRef]

84. Potter, T.J.; Li, Y.; Ward, M.D.; Ellman, J.A. Rh(III)-catalyzed synthesis of isoquinolones and 2-pyridones by annulation of N-methoxyamides and nitroalkenes. Eur. J. Org. Chem. 2018, 4381-4388. [CrossRef]

85. Yao, X.; Li, C.-J. Water-triggered and gold(I)-catalyzed cascade addition/cyclization of terminal alkynes with ortho-alkynylaryl aldehyde. Org. Lett. 2006, 8, 1953-1955. [CrossRef]

86. Ju, J.; Hua, R. Copper-catalyzed synthesis of isoquinolines by the cyclocondensation of ortho-alkynyl aromatic aldehydes or ketones with urea. Curr. Org. Synth. 2013, 10, 328-332. [CrossRef]

87. Dell'Acqua, M.; Castano, B.; Cecchini, C.; Pedrazzini, T.; Pirovano, V.; Rossi, E.; Caselli, A.; Abbiati, G. Mild regiospecific synthesis of 1-alkoxy-isochromenes catalyzed by well-defined [silver(I)(pyridine-containing ligand)] complexes. J. Org. Chem. 2014, 79, 3494-3505. [CrossRef]

88. Jiang, B.; Zhou, Y.; Kong, Q.; Jiang, H.; Liu, H.; Li, J. “One-pot” synthesis of dihydrobenzo[4,5][1,3]oxazino[2,3-a]isoquinolines via a silver(I)-catalyzed cascade approach. Molecules 2013, 18, 814-831. [CrossRef]

89. Mariaule, G.; Newsome, G.; Toullec, P.Y.; Belmont, P.; Michelet, V. Silver-catalyzed domino hydroarylation/cycloisomerization reactions of ortho-alkynylbenzaldehydes: An entry to functionalized isochromene derivatives. Org. Lett. 2014, 16, 4570-4573. [CrossRef]

90. Xiao, T.; Peng, P.; Xie, Y.; Wang, Z.-y.; Zhou, L. Ag(I)-catalyzed three-component reaction of 2-alkynylbenzaldehydes, amines, and diazo compounds. Org. Lett. 2015, 17, 4332-4335. [CrossRef]

91. Liu, H.; Lu, L.; Hua, R. [Cu(maloNHC)]-catalyzed synthesis of 2-aryl pyrazolo[5,1-a]isoquinolines by annulation of $N^{\prime}-(2-$ ((trimethylsilyl)ethynyl)benzylidene)hydrazides with terminal aromatic alkynes. Tetrahedron 2017, 73, 6428-6435. [CrossRef]

92. Zhao, X.; Zhang, G.-X.; Tang, R.-Y.; Deng, C.-L.; Li, J.-H. ZnI -catalyzed benzannulation of $o$-alkynylbenzaldehydes with alkenes leading to 1-acyl-2-substituted naphthalenes. Eur. J. Org. Chem. 2010, 4211-4217. [CrossRef] 
93. Malhotra, D.; Liu, L.-P.; Mashuta, M.S.; Hammond, G.B. Gold-catalyzed annulations of 2-alkynyl benzaldehydes with vinyl ethers: Synthesis of dihydronaphthalene, isochromene, and bicyclo [2.2.2]octane derivatives. Chem. Eur. J. 2013, 19, 4043-4050. [CrossRef] [PubMed]

94. Sakthivel, K.; Srinivasan, K. Indium(III) triflate-catalysed [4 +2] benzannulation reactions of $o$-alkynylbenzaldehydes with enolisable carbonyl compounds: Selective synthesis of naphthyl ketones. Org. Biomol. Chem. 2014, 12, 269-277. [CrossRef]

95. Manojveer, S.; Balamurugan, R. A facile access to substituted benzo[a]fluorenes from $o$-alkynylbenzaldehydes via in situ formed acetals. Chem. Commun. 2014, 50, 9925-9928. [CrossRef]

96. Manojveer, S.; Balamurugan, R. A cascade approach to naphthalene derivatives from $o$-alkynylbenzaldehydes and enolizable ketones via in-situ-formed acetals. Eur. J. Org. Chem. 2015, 4254-4260. [CrossRef]

97. Guo, B.; Zhou, Y.; Zhang, L.; Hua, R. Brønsted acid-promoted one-pot synthesis of chrysene derivatives via isochromenylium intermediate formed in situ. J. Org. Chem. 2015, 80, 7635-7641. [CrossRef]

98. Too, P.C.; Chiba, S. A CuBr-mediated aerobic reaction of 2-alkynylbenzaldehydes and primary amines: Synthesis of 4-bromoisoquinolones. Chem. Commun. 2012, 48, 7634-7636. [CrossRef]

99. Zhang, M.; Zhang, H.-J.; Ruan, W.; Wen, T.-B. Construction of isoquinolin- $(2 H)$-ones by copper-catalyzed tandem reactions of 2-(1-alkynyl)benzaldimines with water. Eur. J. Org. Chem. 2015, 2015, 5914-5918. [CrossRef]

100. Khan, D.M.; Hua, R. Isoquinolone synthesis via $\mathrm{Zn}(\mathrm{OTf})_{2}$-catalyzed aerobic cyclocondensation of 2-(1-alkynyl)benzaldehydes with arylamines. Catalysts 2020, 10, 683. [CrossRef]

101. Miura, T.; Yamauchi, M.; Murakami, M. Synthesis of $1(2 H)$-isoquinolones by the nickel-catalyzed denitrogenative alkyne insertion of 1,2,3-benzotriazin-4(3H)-ones. Org. Lett. 2008, 10, 3085-3088. [CrossRef]

102. Wang, H.; Yu, S. Synthesis of isoquinolones using visible-light-promoted denitrogenative alkyne insertion of 1,2,3benzotriazinones. Org. Lett. 2015, 17, 4272-4275. [CrossRef]

103. Kajita, Y.; Matsubara, S.; Kurahashi, T. Nickel-catalyzed decarbonylative addition of phthalimides to alkynes. J. Am. Chem. Soc. 2008, 130, 6058-6059. [CrossRef]

104. Min, X.-T.; Ji, D.-W.; Zheng, H.; Chen, B.-Z.; Hu, Y.-C.; Wan, B.; Chen, Q.-A. Cobalt-catalyzed regioselective carboamidation of alkynes with imides enabled by cleavage of $\mathrm{C}-\mathrm{N}$ and $\mathrm{C}-\mathrm{C}$ bonds. Org. Lett. 2020, 22, 3386-3391. [CrossRef]

105. Xu, F.; Zhu, W.-J.; Wang, J.; Ma, Q.; Shen, L.-J. Rhodium-catalyzed synthesis of substituted isoquinolones via a selective decarbonylation/alkyne insertion cascade of phthalimides. Org. Biomol. Chem. 2020, 18, 8219-8223. [CrossRef]

106. Zheng, Z.; Alper, H. Palladium-catalyzed carbonylation-decarboxylation of diethyl(2-iodoaryl)malonates with imidoyl Chlorides: An efficient route to substituted isoquinolin-1(2H)-ones. Org. Lett. 2008, 10, 4903-4906. [CrossRef]

107. He, Y.; Yuan, C.; Jiang, Z.; Shuai, L.; Xiao, Q. Expeditious synthesis of isoquinolone derivatives by rhodium(I)-catalyzed annulation reaction through C-C bond cleavage. Org. Lett. 2019, 21, 185-189. [CrossRef]

108. Couture, A.; Deniau, E.; Grandclaudon, P.; Woisel, P. A new synthetic route to 2-alkyl-4-aryl-1(2H)-isoquinolones and 2-alkyl-4aryl-1,2,3,4-tetrahydroisoquinolines. Tetrahedron 1996, 52, 4433-4448. [CrossRef]

109. Sashida, H.; Kawamukai, A. Palladium-catalyzed intramolecular cyclization of $o$-ethynylbenzoic acids and $o$-ethynylbenzamides: Preparation of isocoumarins and isoquinolin-1-ones. Synthesis 1999, 1999, 1145-1148. [CrossRef]

110. Cherry, K.; Duchêne, A.; Thibonnet, J.; Parrain, J.-C.; Abarbri, M. Regioselective synthesis of 1,4,6-trisubstituted-2-pyridinones and 2,3-disubstituted (2H)-isoquinolin-1-ones via tandem stille reaction/heterocyclisation. Synthesis 2005, 2005, 2349-2356.

111. Antczak, M.I.; Ready, J.M. Two-, three- and four-component coupling to form isoquinolones based on directed metalation. Chem. Sci. 2012, 3, 1450-1454. [CrossRef]

112. Lu, W.-D.; Lin, C.-F.; Wang, C.-J.; Wang, S.-J.; Wu, M.-J. Substituent effect on anionic cycloaromatization of 2-(2-substituted ethynyl)benzonitriles and related molecules. Tetrahedron 2002, 58, 7315-7319. [CrossRef]

113. Li, J.; Chen, L.; Chin, E.; Lui, A.S.; Zecic, H. Platinum(II)-catalyzed intramolecular cyclization of alkynylbenzonitriles: Synthesis of 1-alkoxyisoquinolines and isoquinolones. Tetrahedron Lett. 2010, 51, 6422-6425. [CrossRef]

114. Batchu, V.R.; Barange, D.K.; Kumar, D.; Sreekanth, B.R.; Vyas, K.; Reddy, E.A.; Pal, M. Tandem C-C coupling-intramolecular acetylenic Schmidt reaction under Pd/C-Cu catalysis. Chem. Commun. 2007, 19, 1966-1968. [CrossRef]

115. Mondal, A.; Kundu, P.; Jash, M.; Chowdhury, C. Palladium-catalyzed stereoselective synthesis of 4-(diarylmethylidene)- 3,4dihydroisoquinolin-1(2H)-ones: Expedient access to 4-substituted isoquinolin-1(2H)-ones and isoquinolines. Org. Biomol. Chem. 2018, 16, 963-980. [CrossRef]

116. Toure, M.; Jaime-Figueroa, S.; Burslem, G.M.; Crews, C.M. Expeditious synthesis of isoquinolones and isocoumarins with a vinyl borane as an acetylene equivalent. Eur. J. Org. Chem. 2016, 2016, 4171-4175. [CrossRef]

117. Takwale, A.D.; Jeon, Y.U.; Lee, D.H.; Kim, H.J.; Hwang, J.Y. Efficient and rapid synthesis of N-substituted isoquinolin-1-ones under mild conditions: Facile access to doryanine derivatives. Tetrahedron Lett. 2019, 60, 1259-1261. [CrossRef]

118. Annamalai Senthilvelan, A.; Ramakrishnan, V.T. A new photochemical synthesis of benzoxazolo[3,2- $b$ ]isoquinolin-11-one and isoquinolino[3,2-b][1,3]benzoxazin-11-one. Tetrahedron Lett. 2002, 43, 8379-8381. [CrossRef]

119. Jagtap, P.G.; Baloglu, E.; Southan, G.; Williams, W.; Roy, A.; Nivorozhkin, A.; Landrau, N.; Desisto, K.; Salzman, A.L.; Szabó, C. Facile and convenient syntheses of 6,11-dihydro-5H-indeno[1,2-c]isoquinolin-5-ones and 6,11-dihydro-5H-indolo[3,2-c]isoquinolin-5-one. Org. Lett. 2005, 7, 1753-1756. [CrossRef]

120. Lu, J.; Gong, X.; Yang, H.; Fu, H. Concise copper-catalyzed one-pot tandem synthesis of benzimidazo[1,2- $b$ ]isoquinolin-11-one derivatives. Chem. Commun. 2010, 46, 4172-4174. [CrossRef] 
121. Beng, T.K.; Langevin, S.; Farah, A.O.; Goodsell, J.; Wyatt, K. One-shot access to isoquinolone and(hetero)izidinone architectures using cyclic $\alpha$-chloro eneformamides and cyclic anhydrides. New J. Chem. 2019, 43, 5282-5286. [CrossRef]

122. Yuki Fukui, Y.; Liu, P.; Liu, Q.; He, Z.-T.; Wu, N.-Y.; Tian, P.; Lin, G.-Q. Tunable arylative cyclization of 1,6-enynes triggered by rhodium(III)-catalyzed C-H activation. J. Am. Chem. Soc. 2014, 136, 15607-15614. [CrossRef]

123. Quiñones, N.; Seoane, A.; García-Fandiño, R.; Mascareñas, J.L.; Gulías, M. Rhodium(III)-catalyzed intramolecular annulations involving amide-directed C-H activations: Synthetic scope and mechanistic studies. Chem. Sci. 2013, 4, 2874-2879. [CrossRef]

124. Song, L.; Tian, G.; He, Y.; Van der Eycken, E.V. Rhodium(III)-catalyzed intramolecular annulation through C-H activation: Concise synthesis of rosettacin and oxypalmatime. Chem. Commun. 2017, 53, 12394-12397. [CrossRef]

125. Song, L.; Tian, G.; Van der Eycken, E.V. Rhodium(III)-catalyzed intermolecular cascade annulation through C-H activation: Concise synthesis of rosettacin. Mol. Catal. 2018, 459, 129-134. [CrossRef]

126. Reddy, C.R.; Mallesh, K. Rh(III)-catalyzed cascade annulations to access isoindolo[2,1-b]isoquinolin-5(7H)-ones via C-H activation: Synthesis of rosettacin. Org. Lett. 2018, 20, 150-153. [CrossRef]

127. Hong, S.Y.; Jeong, J.; Chang, S. [4+2] or [4+1] Annulation: Changing the reaction pathway of a rhodium-catalyzed process by tuning the Cp ligand. Angew. Chem. Int. Ed. 2017, 56, 2408-2412. [CrossRef]

128. Chen, F.; Lai, S.-Q.; Zhu, F.-F.; Meng, Q.; Jiang, Y.; Yu, W.; Han, B. Cu-catalyzed radical cascade annulations of alkyne-tethered Nalkoxyamides with air: Facile access to isoxazolidine/1,2-oxazinane-fused isoquinolin-1(2H)-ones. ACS Catal. $2018,8,8925-8931$. [CrossRef]

129. Zhang, L.-B.; Geng, R.-S.; Wang, Z.-C.; Ren, G.-Y.; Wen, L.-R.; Li, M. Electrochemical intramolecular C-H/N-H functionalization for the synthesis of isoxazolidine-fused isoquinolin-1(2H)-ones. Green Chem. 2020, 22, 16-21. [CrossRef]

130. Wen, L.-R.; Ren, G.-Y.; Geng, R.-S.; Zhang, L.-B.; Li, M. Fast construction of isoquinolin-1(2H)-ones by direct intramolecular $\mathrm{C}-\mathrm{H} / \mathrm{N}-\mathrm{H}$ functionalization under metal-free conditions. Org. Biomol. Chem. 2020, 18, 225-229. [CrossRef]

131. Gollapelli, K.K.; Kallepu, S.; Govindappa, N.; Nanubolu, J.B.; Chegondi, R. Carbonyl-assisted reverse regioselective cascade annulation of 2-acetylenic ketones triggered by Ru-catalyzed C-H activation. Chem. Sci. 2016, 7, 4748-4753. [CrossRef]

132. Mukherjee, K.; Shankar, M.; Ghosh, K.; Sahoo, A.K. An orchestrated unsymmetrical annulation episode of C(sp $\left.{ }^{2}\right)-\mathrm{H}$ bonds with alkynes and quinones: Access to spiro-isoquinolones. Org. Lett. 2018, 20, 1914-1918. [CrossRef]

133. Yoshida, J.-I.; Kataoka, K.; Horcajada, R.; Nagaki, A. Modern strategies in electroorganic synthesis. Chem. Rev. 2008, 108, 2265-2299. [CrossRef]

134. Francke, R.; Little, R.D. Redox catalysis in organic electrosynthesis: Basic principles and recent developments. Chem. Soc. Rev. 2014, 43, 2492-2521. [CrossRef]

135. Yan, M.; Kawamata, Y.; Baran, P.S. Synthetic organic electrochemical methods since 2000: On the verge of a renaissance. Chem. Rev. 2017, 117, 13230-13319. [CrossRef]

136. Jiang, Y.; Xu, K.; Zeng, C. Use of electrochemistry in the synthesis of heterocyclic structures. Chem. Rev. 2018, 118, 4485-4540. [CrossRef]

137. Martins, G.M.; Zimmer, G.C.; Mendesd, S.R.; Ahmed, N. Electrifying green synthesis: Recent advances in electrochemical annulation reactions. Green Chem. 2020, 22, 4849-4870. [CrossRef]

138. Beeler, A. Special issue introduction: Photochemistry in organic synthesis. Chem. Rev. 2016, 116, 9629-9630. [CrossRef]

139. Marzo, L.; Pagire, S.K.; Reiser, O.; König, B. Visible-light photocatalysis: Does it make a sifference in organic synthesis? Angew. Chem. Int. Ed. 2018, 57, 10034-10072. [CrossRef]

140. Petzold, D.; Giedyk, M.; Chatterjee, A.; König, B. A retrosynthetic approach for photocatalysis. Eur. J. Org. Chem. 2019, 2020, 1193-1244. [CrossRef]

141. Cannalire, R.; Pelliccia, S.; Sancineto, L.; Novellino, E.; Tron, G.C.; Giustinian, M. Visible light photocatalysis in the late-stage functionalization of pharmaceutically relevant compounds. Chem. Soc. Rev. 2021, 50, 766-897. [CrossRef] [PubMed]

142. Tang, S.; Wang, D.; Liu, Y.; Zeng, L.; Lei, A. Cobalt-catalyzed electrooxidative C-H/N-H [4 + 2] annulation with ethylene or ethyne. Nat. Commun. 2018, 9, 798. [CrossRef] [PubMed]

143. Tian, C.; Massignan, L.; Meyer, T.H.; Ackermann, L. Electrochemical C-H/N-H activation by water-tolerant cobalt catalysis at room temperature. Angew. Chem. Int. Ed. 2018, 57, 2383-2387. [CrossRef] [PubMed]

144. Mei, R.; Sauermann, N.; Oliveira, J.C.A.; Ackermann, L. Electroremovable traceless hydrazides for cobalt-catalyzed electrooxidative C-H/N-H activation with internal alkynes. J. Am. Chem. Soc. 2018, 140, 7913-7921. [CrossRef] [PubMed]

145. Kalsi, D.; Dutta, S.; Barsu, N.; Rueping, M.; Sundararaju, B. Room-temperature C-H bond functionalization by merging cobalt and photoredox catalysis. ACS Catal. 2018, 8, 8115-8120. [CrossRef]

146. Wang, Z.-Q.; Hou, C.; Zhong, Y.-F.; Lu, Y.-X.; Mo, Z.-Y.; Pan, Y.-M.; Tang, H.-T. Electrochemically enabled double C-H activation of amides: Chemoselective synthesis of polycyclic isoquinolinones. Org. Lett. 2019, 21, 9841-9845. [CrossRef]

147. Zhao, Y.; Shi, C.; Su, X.; Xia, W. Synthesis of isoquinolones by visible-lightinduced deaminative [4+2] annulation reactions. Chem. Commun. 2020, 56, 5259-5262. [CrossRef] 